\title{
Les milieux antisémites anversois. Portraits de "chasseurs de Juifs" avant et durant la guerre
}

Lieven Saerens

\section{(2) OpenEdition}

1 Journals

Édition électronique

URL : http://journals.openedition.org/cmc/325

DOI : $10.4000 / \mathrm{cmc} .325$

ISSN : 2684-3080

Éditeur

Fondation de la Mémoire Contemporaine

Édition imprimée

Date de publication : 1 décembre 2016

Pagination : 13-61

ISSN : 1377-1256

Référence électronique

Lieven Saerens, "Les milieux antisémites anversois. Portraits de "chasseurs de Juifs" avant et durant la guerre ", Les Cahiers de la Mémoire Contemporaine [En ligne], 12 | 2016, mis en ligne le 05 novembre 2019, consulté le 08 septembre 2020. URL : http://journals.openedition.org/cmc/325 ; DOI : https:// doi.org/10.4000/cmc.325 


\section{Les milieux antisémites anversois \\ Portraits de "chasseurs de Juifs" avant et durant la guerre}

\section{Lieven Saerens}

C'est la découverte aux Archives de la Ville d'Anvers (Felixarchief) d'une photographie représentant Gustaaf Vanniesbecq, Antoon Lint et René Bollaerts en uniformes de la milice flamande (Vlaamsche Militie) qui est à l'origine de la présente contribution. J'avais au cours de mes recherches déjà relevé les noms de ces trois hommes, antisémites d'avant-guerre, nazis de la première heure et "chasseurs de Juifs" sous l'Occupation. Ce n'est pas un hasard s'ils prennent fraternellement la pose sur la photographie en question. Tous trois ont en effet eu un parcours similaire, que l'on s'attachera à retracer ici, en l'insérant dans l'histoire des organisations auxquelles ils ont pris part. En s'inscrivant dans le vaste mouvement de recherche sur la persécution des Juifs de Belgique, ce texte entend rendre disponibles toute une série de données sur les "chasseurs de Juifs" du milieu anversois et dresser la carte des différents groupements antijuifs, qu'ils soient d'orientation nationaliste belge ou nationaliste flamande ${ }^{1}$.

\section{Prémices de la "chasse aux Juifs" : de la Vlaamsche Militie au Verdi- naso}

La Vlaamsche Militie (Milice flamande), un groupe de défense nationaliste flamand d'environ quarante hommes, fut créée à Anvers en 1930 par Jef Missoorten, ancien volontaire de guerre et tailleur de profession. Ses membres, armés d'un bâton, étaient vêtus d'un uniforme kaki, d'une casquette et de bottes de couleur noire. Parmi eux se trouvaient Gustaaf Vanniesbecq, René Bollaerts et Antoon Lint. Vanniesbecq, né le 25 novembre 1913 à Deurne, était mécanicien de profession. Véritable truand, il eut une enfance difficile, se retrouvant très vite

${ }^{1}$ Traduit du néerlandais par Barbara Dickschen, hormis certains passages traduits par Serge Govaerts pour l'ouvrage de Lieven Saerens Étrangers dans la cité. Anvers et ses Juifs, Bruxelles, 2005. Texte revu par la Fondation de la Mémoire contemporaine. 
devant le juge de la jeunesse. Il devient portier d'un boui-boui du quartier de la gare d'Anvers et proxénète. Après-guerre, cela poussera le quotidien socialiste anversois Volksgazet à le qualifier railleusement de «Horst Wessel raté de Flandre », en référence à ce membre notoire du NSDAP qui avait également été souteneur ${ }^{2}$. Au début des années 1930, Vanniesbecq fut accusé du meurtre d'un agent de change mais libéré faute de preuves. C'est à cette époque qu'il rejoignit la Vlaamsche Militie. Il aurait entre-temps également flirté avec le communisme.

Gustaaf Vanniesbecq était le fils aîné de l'officier du génie Antoine Vanniesbecq, ancien combattant, invalide de guerre et catholique pratiquant. Ce dernier avait des convictions politiques tout autres que son fils. Dans l'entre-deux-guerres, il devint un fervent militant du Mouvement wallon et se montra un partisan acharné du rattachement de la Wallonie à la France.

René Bollaerts, le fils d'un marchand de charbon, est également né à Deurne, le 18 octobre 1915. Issu d'une famille catholique, il fréquenta l'école communale de Deurne jusqu'à 15 ans. Apparemment épileptique, un rapport psychiatrique d'après-guerre le décrit comme « un enfant souffreteux $»^{3}$. Par l'entremise d'une de ses belles-sœurs, tailleuse de diamants, il devint ouvrier dans l'industrie diamantaire, mais dut quitter l'atelier en raison de «différends » avec son employeur (juif ?).

Employé dans l'affaire de son père, un « désaccord » avec ses parents le fit retourner dans le secteur diamantaire, alors durement frappé par la crise. Se retrouvant régulièrement au chômage, il suivit un an durant des cours à l'école d'aviation à Anvers. Mais la guerre l'empêcha de décrocher son brevet. Certaines photographies le révèlent marin sur le Léopoldville. C'est probablement ainsi qu'en 1933 il fit la connaissance de Hylal Wladislawa, la belle-fille d'un capitaine de la marine allemande, qu'il épouse en 1935. Un article du journal antisémite Volksverwering, nous apprend qu'elle aurait tout comme son mari

2 Volksgazet, « Naar de Bronnen van het Verraad. De mislukte Horst Wessel van Vlaanderen », 12 et 13-14.1.1945.

3 Auditorat militaire, Dossier René Bollaerts. Rapport du psychiatre Andersen, 28.1.1947. 
éprouvé des sentiments antijuifs ${ }^{4}$. En 1938, Bollaerts de mère allemande, demanda (en vain) la nationalité allemande. La même année, il devint également membre du groupuscule nazi anversois Dietsche Arbeiderspartij (Parti des travailleurs thiois).

Sur les photographies, René Bollaerts a l'allure d'un dandy, en costume trois-pièces, avec une canne et des gants à la main, et ce malgré une situation financière précaire. Une photo de lui derrière son chevalet en compagnie de deux enfants nous montre une fibre artistique. Une autre de son épouse dans leur maison fait découvrir un bel intérieur de style moderne.

Antoon Lint, plombier de profession, habitait à Berchem où il vit le jour le 14 avril 1914.

Le 30 novembre 1931, Jef Missoorten passa avec sa Vlaamsche Militie (Milice flamande) anversoise au Verdinaso (Verbond van Dietsche Nationaal Solidaristen - Union des national-solidaristes thiois), dont le leader n'était autre que Joris Van Severen, gandin charismatique originaire de Flandre occidentale. Le lendemain, le $1^{\text {er }}$ décembre 1931, fut fondé à Anvers le premier noyau du Verdinaso dont le local se trouvait d'abord rue Saint-Gommaire (Sint-Gummarusstraat). Finalement, le Verdinaso aboutira à la Dietsch Huis (Maison thioise) (Italiëlei 239), où se réunissait également le Kristene Vlaamsche Volkspartij (Parti populaire chrétien flamand) de l'avocat René Lagrou, à un certain moment membre du Verdinaso. L'aménagement de ce local aurait, selon certaines rumeurs, été financé avec de l'argent allemand.

Le 10 juillet 1932, Joris Van Severen nomma Jef Missoorten commandant national de la Dinaso Militie (Milice de la Dinaso). Le chef de la section anversoise était Arthur Nollet, et Antoon Lint devint successivement chef d'équipe de la section anversoise de la Dinaso Militie et vendelleider (chef de compagnie) du Dinaso Militanten Orde (Ordre des Militants du Dinaso), fonction qu'il conserva au moins jusqu'à la fin 1936.

On apprit bien vite que Jef Missoorten avait des sympathies nationales-socialistes. Dans la région anversoise, le noyau des membres qui cherchaient leur inspiration dans une idéologie nationale-socialiste populaire («völkisch ») était particulièrement étoffé. Gustaaf Vannies-

\footnotetext{
${ }^{4}$ Auditorat militaire, Dossier René Bollaerts.
} 
becq, René Bollaerts et Antoon Lint y appartenaient. Lint ne faisait d'ailleurs pas mystère de son admiration pour l'Allemagne nazie. Il donna par exemple lecture devant la section du Verdinaso de Bornem, le 20 janvier 1936, d'extraits du livre De strijd om Berlijn (Le combat pour Berlin), une traduction néerlandaise de Kampf um Berlin (Berlin, 1932) du Reichsleiter für Propaganda (gouverneur du Reich en charge de la propagande) du NSDAP Joseph Goebbels. « Nous devons aiguiser nos forces, aiguiser notre volonté comme un diamant acéré », concluait-il, "pour trancher ensuite d'un coup impitoyable toutes les pourritures, les saletés, les mesquineries et les petitesses qui nous entourent $\aleph^{5}$.

Des membres du Verdinaso agressaient de temps à autre des Juifs à Anvers ou déclenchaient des bagarres dans les rues. La cause de ces incidents n'était jamais très claire, mais le fait qu'ils avaient souvent lieu juste après des manifestations de protestation de la communauté juive d'Anvers, et fréquemment le week-end, n'est sans doute pas une coïncidence.

Le 20 avril 1933, une poignée de membres de la communauté juive avaient manifesté devant le consulat allemand à Anvers et un carreau avait été brisé. Quelques jours plus tard, le 23 avril, cinq membres de la milice Dinaso, âgés de 18 à 25 ans, s'étaient promenés en uniforme et armés de matraques dans le quartier juif, cherchant manifestement la provocation, voulant faire honneur à leur réputation de "bagarreurs". Gustaaf Vanniesbecq et René Bollaerts faisaient partie du commando. Mais les choses ne tournèrent pas comme prévu. Ils furent accueillis par des sifflets, puis, au coin de la rue des Fortifications (Vestingstraat) et de la rue du Pélican (Pelikaanstraat), " pris en mains et solidement rossés » par des Juifs ${ }^{6}$. La situation dégénéra à un point tel que la police dut intervenir avec des matraques pour délivrer les Dinasos, avant de les amener au poste. Une heure plus tard, ils purent regagner leur local sous protection policière ${ }^{7}$.

\footnotetext{
5 Hier Dinaso!, 25.1.1936. Dans un souci de lisibilité, nous avons choisi de traduire systématiquement les extraits des documents rédigés en néerlandais et en allemand.

6 De Volksgazet, "Vlaamsche fascisten door Joden afgeranseld te Antwerpen », 24.4.1933, p. 1 .

7 FelixArchief (Anvers) MA, 27960, Pv police de la 6e section, 26 avril $1933\left(\mathrm{PV} \mathbf{n}^{\circ}\right.$ 1514).
} 
À l'été 1934, les Allemands commencèrent à se méfier du Verdinaso. Les principales raisons de ce changement d'attitude résidaient dans le projet de Joris Van Severen de donner à son mouvement une « Nouvelle Orientation » (« Nieuwe Marsrichting ») - projet qui allait entraîner en juillet 1934 une rupture avec le «nationalisme populaire » («volksnationalisme ») et l'antibelgicisme radical - ainsi que dans les contacts supposés entretenus avec des milieux fascistes francophones. La « Nouvelle Orientation » eut pour effet d'écarter du Verdinaso un certain nombre d'antisémites et de nationaux-socialistes avérés comme Vanniesbecq. Mais cette nouvelle politique ne fut pas la seule cause du déclin du Verdinaso. Les conflits internes se multipliaient, débouchant en août 1934 sur la démission d'Arthur Nollet, le chef de la Dinaso Militie d'Anvers. Environ deux mois plus tard, Nollet fonda avec Vanniesbecq et l'antisémite et nazi convaincu Ward Hermans le DinasoOppositieblok (Bloc d'Opposition au Dinaso).

À partir de la fin des années 1920, Hermans séjourna régulièrement en Allemagne et entretint des contacts avec des agents allemands de l'Abwehr. Il avait participé en 1932 au Deutsch-Nordisch Kongress (Congrès germano-nordique) à Rostock, où l'on prêcha l'idée (nationale-socialiste) d'une "supériorité nordique". Lors de son voyage de retour, il fit étape à Berlin où il assista à un meeting électoral de Joseph Goebbels et Adolf Hitler. Au début des années 1930, il se lança dans la publication de brochures antijuives. Son Jodendom, Marxisme en wereldheerschappij. Levensvraagstukken voor ons volk! Vlaamsche nationalisten dit is voor $u$ ! (Judaïsme, Marxisme et complot mondial. Questions existentielles pour notre peuple! Nationalistes flamands, ceci est pour vous!), publié en 1933, connut un réel succès dans les milieux antijuifs et se trouvait fréquemment recommandé dans les publications antisémites ${ }^{8}$.

Le Dinaso-Oppositieblok s'exprimait dans la revue Dietschland en Orde (Pays thiois et ordre), qui s'arrêta après quelques numéros. L'organisation admettait être « antisémite », entendant par là qu'elle

\footnotetext{
8 Au nombre de ses autres publications : W. Hermans, Het boek der stoute waarheden. West-Europeesche perspectieven, Langemark, 1933 ; Id., West-Europeesche perspectieven. ' $t$ Wordend Dietschland in 't worden van den tijd, Anvers, [1934 ?]; Id., Jodendom en communisme zonder masker. Nog stoute waarheden, Langemark, 1936 ; Id., Van Egger tot Jasina. 100 dagen in Tsjecho-Slowakije, Langemark, 1938.
} 
voulait « retirer (aux Juifs) les libertés civiques, les possibilités de naturalisation et empêcher leur assimilation à la population thioise ». Connaissant les contacts antérieurs de Ward Hermans avec les cercles "neutres" d'indépendants (en fait des sympathisants de l'Ordre Nouveau), la carte antisémite allait pratiquement de soi : « Compatriote, n'achète pas chez le Juif », pouvait-on lire dans Dietschland en Orde ${ }^{9}$.

\section{Le Volksverwering et l'affirmation des tendances nationales- socialistes}

On retrouve Gustaaf Vanniesbecq, Antoon Lint et René Bollaerts en 1937 au sein de Volksverwering (La défense du peuple), l'organisation antisémite créée cette même année par l'avocat anversois René Lambrichts. L'examen de ce mouvement montre les différents modes de rapprochement des milieux antijuifs anversois avec le national-socialisme allemand. Assez curieusement, s'y côtoyaient tout autant des nationalistes flamands que des nationalistes belges, réunis par leur haine commune des Juifs. Lambrichts était lui-même un nationaliste belge et, dès 1935 - dans le cadre de la « Nouvelle Orientation »- membre du Verdinaso. Il était le fils d'un médecin respecté de Borgerhout, un « catholique pieux ». Il avait été auparavant membre de diverses organisations nationalistes belges et antijuives, telles que la Vaderlandsche Jeugd (Jeunesse patriotique), les Jonge Belgen (JB Jeunes Belges), le Nationaal Corporatief Arbeidersverbond (NACO Union nationale corporative des Ouvriers) et la Nationaal Legioen (Légion nationale).

À 17 ans, René Lambrichts souhaitait entrer dans les ordres dominicains. Toutefois, après quelques mois, il y renonça. Après ses humanités au collège Sint-Jan Berchmans d'Anvers, son père l'obligea à étudier les sciences à l'Université catholique de Louvain. Cela ne plut pas à Lambrichts, qui s'enfuit à Paris, où il signa pour cinq ans à la Légion étrangère. Selon le rapport d'après-guerre d'un psychiatre judiciaire, « il participa à la vie débraillée des soldats [...] buvant parfois de manière excessive, fréquentant les prostituées et vivant agréablement ${ }^{10}$. À son retour de la Légion étrangère, Lambrichts entama des

\footnotetext{
${ }^{9}$ Dietschland en Orde, 7.11.1934, pp. 3-4.

${ }_{10}$ Auditorat militaire, Dossier Volksverwering.
} 
études de droit à l'ULB, qu'il termina. Il commença son stage au barreau de Bruxelles et y rencontra sa future épouse. Rappelé à Anvers par son père, il devint dès le début des années 1930 un fasciste convaincu et un nationaliste belge. D'après ses dires, ce sont les « magouilles politiques » et le népotisme dans la profession juridique qui l'ont mené au fascisme. Le rapport psychiatrique précise : « Le climat antisémite, né des difficultés économiques dans les années de crise, a trouvé un large écho dans l'opinion mécontente. Lambrichts, un de ses porte-parole, s'empara avec enthousiasme de l'argument et récolta de la sorte au sein de ce milieu un accueil très favorable. Ceci lui conféra une certaine aura politique et, en même temps, lui rapporta des affaires judiciaires. » Vanniesbecq devint « Chef de Propagande » (Algemeen Propagandaleider) de Volksverwering et Lint « Secrétaire de Propagande » (Algemeen Propagandasecretaris).

Le 24 janvier 1937, l'organe de presse du même nom, Volksverwering, parut pour la première fois, avec pour sous-titre Propagandablad ter Beveiliging van Bloed en Bodem (Feuille de propagande pour la défense $d u$ sang et $d u$ sol). Le périodique connut une croissance continue en nombre d'abonnés: en mars 1938, il y avait 316 abonnés et en décembre 1939 75411. Volksverwering poursuivait la voie antisémite tracée par le NACO, empreinte de racisme biologique et d'idéologie nationale-socialiste. Le slogan de Volksverwering ne laissait pas de place au doute quant aux visées racistes de l'organisation du même nom et était emprunté au juriste et promoteur d'art socialiste bruxellois Edmond Picard (1836-1924) : « Je vous le dis en vérité : un temps viendra, qui n'est pas loin, où toutes les connaissances et toutes les institutions humaines, l'Histoire surtout et les Lois seront révisées d'après la Race. „12

Les Juifs étaient décrits dans le journal de Volksverwering comme « un groupe de parasites héréditairement contaminés par l’ignominie, la bassesse et l'immoralité », dont l'influence devait « inconditionnellement » être « brisée » : « Ils doivent être extirpés de notre peuple et leur domination mondiale doit être à jamais entravée ». Pour ces rai-

\footnotetext{
11 Archives générales du Royaume Anvers-Beveren (ARA), Archives du Parquet du Procureur du Roi d'Anvers, Archives de la brigade de la police judiciaire du Parquet d'Anvers, Versement $2001 \mathrm{C}$.

12 E. Picard, Synthèse de l'antisémitisme : la Bible et le Coran, les hymnes vediques : l'art arabe, les juifs au Maroc, Bruxelles, 1892.
} 
sons-là, les frontières devaient restées fermées aux Juifs, aucune naturalisation ne devait encore être octroyée « et toutes celles existantes devraient être annulées ${ }^{13}$. Chaque année, $10 \%$ «en plus de l'excédent de naissance » des Juifs immigrés devaient être expulsés « vers... ce que nous appellerons le Judland $»^{14}$. Les lois antijuives de l'Allemagne nazie furent approuvées, ce qui, en clair, signifiait que les réfugiés juifs ne pouvaient compter sur aucune compassion : «Nous avons affaire ici à des gens, qui de par leur activité nuisible se sont fait expédier avec armes et bagages hors des frontières par le peuple allemand. $»^{15} \mathrm{Il}$ fallait se méfier de ceux qui avaient un autre avis au sujet des Juifs, ou qui fréquentaient des Juifs : « Le valet des Juifs est un traître du peuple ». Autre trait révélateur du radicalisme de Volksverwering : l'organisation militait pour la stérilisation de personnes porteuses d'une maladie héréditaire, un point de vue inspiré en partie par le film de propagande nazi Erbkrank (1936) d'Herbert Gerder.

À l'instar de son prédécesseur NACO, Volksverwering s'intéressa dès le départ aux ouvriers diamantaires anversois. L'industrie diamantaire fut très durement touchée par la crise économique. Ainsi, dans Volksverwering, paraissaient les rubriques Bij onze Diamantbewerkers (Chez nos ouvriers diamantaires) et Om en rond "onze" Belgische diamantnijverheid (À propos de "notre' industrie diamantaire belge). À partir de mars 1938 environ, Volksverwering se lança également dans la distribution assidue de son journal et d'autres publications aux alentours des ateliers diamantaires et, peu après, créa le Comité d'Action des Ouvriers diamantaires belges (Aktiekomiteit der Belgische Diamantbewerkers). C'est donc fort logiquement qu'à partir de juin 1938, René Lambrichts prit de temps à autre la parole devant des ouvriers diamantaires au chômage.

Volksverwering tentait également de prendre pied dans les milieux des classes moyennes, en particulier dans les organisations de classes moyennes dites "neutres", en réalité gagnées aux idées de l'Ordre nouveau. Lorsque fut créée le 8 janvier 1937, presque au même moment où Volksverwering vit le jour, la Korporatieve Unie van de Middenstand (Union corporative des Classes moyennes), dite "neutre", René Lam-

\footnotetext{
13 Volksverwering, « Zijn de joden slecht door reactie ? », 4.4.1937, p. 2.

14 Ibid., « Hoe Brabo de jodenkwestie zou oplossen », 16.5,1937, p. 2.

15 Ibid., 28.2.1937, p. 3.
} 
brichts s'y affilia immédiatement. Cette Union corporative devint le lien entre les "catholiques de parti" (bruxellois) et les associations des classes moyennes qui étaient passées à Rex et au Eenheidsfront (Front pour l'Unité), l'organisation "neutre" des classes moyennes. Lambrichts collabora sous le pseudonyme Lambert au journal de la Korporatieve Unie (Union corporative), qui avait pour titre évocateur $D e$ Nieuwe Orde (L'Ordre nouveau) (1937) et comptait dans ses pages de nombreuses contributions antijuives. Lambrichts tint en outre une conférence pour Het Recht (Le Droit), une organisation des classes moyennes "neutre" de la métropole flamande.

Volksverwering entretint probablement d'emblée d'étroites relations avec l'Allemagne nazie. On y trouve dès le premier numéro de sa publication de la propagande pour le Welt-Dienst (Service mondial), noyau du mouvement antisémite international, qui lui rendait la pareille dans son bulletin.

De nombreux membres de Volksverwering étaient en outre abonnés aux publications de l'organisation allemande Fichte Bund (Ligue Fichte), qui se chargeait de diffuser la propagande nazie à l'étranger. On trouvait parmi ces abonnés Vanniesbecq, Bollaerts et Lint. Vanniesbecq avait également des contacts avec l'Auslands-Organisation (Organisation pour l'Étranger) de la NSDAP.

Vers février 1938, René Lambrichts envoya Gustaaf Vanniesbecq auprès du dirigeant de l'organisation antisémite anversoise AntiJoodsch Front (Front antijuif) Emiel Francken, fils illégitime d'un artiste peintre anversois, afin qu'il leur prête main-forte pour expulser les Juifs du parc municipal. Pour des motifs opportunistes, l'AntiJoodsch Front refusa d'accéder à cette requête, non qu'il condamnât par principe le recours à la violence, mais le groupuscule craignait que cela ne pousse le gouvernement à promulguer des mesures de protection en faveur des Juifs et ne fasse taire les organisations antijuives.

D'ailleurs, dans la publication homonyme de l'Anti-Joodsch Front parurent diverses contributions n'ayant rien à envier à celles de Volksverwering. Le 15 septembre 1938, Emiel Francken écrivait : « La vie des peuples est le fait d'une lutte éternelle entre les forts, les nobles, d'un point de vue raciste, les supérieurs et les inférieurs. Cet ennemi redoutable doit être écrasé. Ce Juif, maître du monde, dont la voie est tracée par le bolchevisme. Il faudra donc engager le combat. Et, 
comme dans chaque combat, il n'y a que deux possibilités. Ou bien nous terrassons l'ennemi définitivement, ou bien c'est nous qui sombrerons. Les Juifs sont les maîtres du monde ! Le Juif est le vrai diable et le déclin de l'humanité. Il s'agit d'un combat du prédateur contre l'humain. Les Juifs dehors et pour toujours !!! Cette sale race. À présent retentit le cri d'alarme, repris en choeur par d'innombrables haïsseurs de Juifs dans le monde entier. ${ }^{16}$

\section{Réorganisation de Volksverwering et création de l'Actie-Groep}

En mars 1938, Volksverwering subit une réorganisation en profondeur. Les contacts avec l'Allemagne s'intensifièrent et les tendances nationales-socialistes s'affirmèrent. Le 18 mars, l'organisation se transforma en association sans but lucratif (asbl). Parmi les signataires de l'acte de fondation figuraient Lambrichts (désigné président) et Vanniesbecq. L'objet social était triple : «1. Combattre l'influence juive dans la vie publique et privée du pays ; 2 . Combattre les forces secrètes qui favorisent l'immigration juive; 3 . Militer pour la réconciliation des peuples aryens, garantir le maintien de la paix et de la civilisation chrétienne $»^{17}$.

Vers la même période fut créé, sous la direction générale de Gustaaf Vanniesbecq, le groupe paramilitaire Actie-Groep (A-G, Groupe d'Action). Les membres portaient un uniforme noir. Leur drapeau était également noir, avec en son milieu la rune blanche représentant la Victoire (Sieg), une référence pour le moins très directe à l'Allemagne nazie. Ils s'occupaient du maintien de l'ordre des meetings antijuifs, considérés comme des « soldats » luttant contre « le monstre juif ». La section anversoise de l'A-G expulsa en effet des Juifs, par la force, du parc municipal. L'un des membres les plus éminents de l'A-G était Antoon Lint. Nous pouvons probablement également compter René Bollaerts parmi ses membres.

À partir du $1^{\text {er }}$ avril 1938, Volksverwering reçut une aide financière du gouvernement allemand. Chaque mois, 100 reichsmarks lui étaient remis par l'intermédiaire du consulat allemand d'Anvers et du Buch-

16 Ceges (Bruxelles), Auditorat militaire, Pièces à conviction, Dossier Anti-Joodsch Front et Archives Emiel Francken et Lode Welter, 1940-1944 (AA 1314).

17 Moniteur belge, 26.3.1938, 299-300. 
halter (comptable) anversois Jozef Baeten, également collaborateur du journal "neutre" anversois Neptune. Baeten était la personne de liaison entre le Propaganda-Ministerium allemand (ministère du Reich à l'Éducation du Peuple et à la Propagande) et René Lambrichts. S'il s'agissait là d'un montant modeste, il n'est pas à exclure que l'organisation bénéficiât d'autres dons, comme ceux d'organismes SS.

Par l'intermédiaire de l'Anversois Constant Van Dessel, bandagiste de profession, des instances allemandes procurèrent à Volksverwering des exemplaires de Der Stürmer, la publication virulemment antisémite de l'idéologue nazi Julius Streicher. Tout comme René Bollaerts, Van Dessel avait d'abord milité au sein de l'organisation Vrienden van het Nieuwe Duitschland (Amis de la nouvelle Allemagne), créée à Anvers en 1937. Il était actif dans le commerce des armes, qui partaient du port d'Anvers à destination d'« organisations arabes » de Palestine (il s'agissait en fait d'organisations proches d'Amin al-Husseini, le Grand Moufti antisémite de Jérusalem). Il appartenait également à la "bande du parc" ("Bende van het Park"), un groupuscule national-socialiste qui se distinguait essentiellement par ses actions de molestation de Juifs dans le parc communal d'Anvers. Il avait toutefois de l'aversion pour Gustaaf Vanniesbecq, en qui il ne pouvait avoir confiance puisqu'il s'agissait du fils d'un ancien officier de l'armée belge. « En outre, dira-t-il à son sujet, il buvait et vivait comme un vagabond. Je trouvais cela pour le moins suspect. ${ }^{18}$

En août 1938, Volksverwering formula, sous la plume de Gustaaf Vanniesbecq, cinq points pour « résoudre énergiquement la question juive », d'inspiration nationale-socialiste : arrêt immédiat de l'immigration juive; expulsion de tous les étrangers "indésirables"; interdiction faite aux Juifs de se mêler de politique; interdiction faite aux Juifs de prendre à leur service des femmes "aryennes"; interdiction de relations sexuelles entre Juifs et "Aryens"19. Lors de meetings, Volksverwering ne voyait pas non plus d'inconvénient à évoquer l'Allemagne nazie. Au cours de la Grande Réunion d'Embrigadement (Groote Werfvergadering) du 28 juin 1938, dans la salle Kathedraal située Marché au Lait (Melkmarkt) à Anvers, une banderole « Les Juifs

18 Auditorat militaire, Dossier Vanniesbecq; Ceges, Dossiers généraux de la Sûreté d'État sur l'Abwehr et la Sipo-SD pendant l'Occupation, 1944-1947 (AA 1312).

19 Volksverwering, 14.8.1938, p. 1. 
sont notre malheur » fut accrochée au-dessus du podium, se référant là directement à la devise de Der Stürmer, le journal de Julius Streicher. Des responsables anversois et bruxellois prirent la parole. Parmi eux, on retrouvait Lambrichts et Vanniesbecq.

Chaque mois, Volksverwering organisait des meetings à Anvers ou dans les communes périphériques à forte population juive, comme Borgerhout et Berchem. Le 10 novembre 1938, il y eut le meeting Kan Kamiel Huysmans nog burgemeester van Antwerpen blijven? (Kamiel Huysmans peut-il encore rester bourgmestre d'Anvers?). Volksverwering affirma que cinq cents auditeurs " enthousiastes » assistèrent au meeting. Quelque trois cents curieux auraient en outre fait le pied de grue à l'extérieur de la salle. Un procès-verbal de la police judiciaire anversoise ne mentionne que trois cents personnes présentes, parmi lesquelles une vingtaine de femmes. Les orateurs étaient René Lambrichts, Gustaaf Vanniesbecq et Jozef Van Dijck, employé et éditeur responsable de la publication de Volksverwering ${ }^{20}$.

Un mois plus tard, le 6 décembre 1938, ce fut le tour de Borgerhout. La manifestation avait été annoncée comme une «assemblée d'ouvriers ». Elle avait pour thème - plus qu'allusif - 120.000 Joden en 120.000 werklozen (120.000 Juifs et 120.000 chômeurs). Selon Volksverwering, ce fut une «brillante réussite». Dans une «salle comble » se tenaient « des centaines de compatriotes ». Selon un procès-verbal de la gendarmerie, il n'y avait cependant que septante personnes présentes, dont une quinzaine de femmes ${ }^{21}$. À l'issue de la réunion, l'A-G de Volksverwering défila dans le "quartier juif" en braillant des chansons : "Partout, les Juifs se montraient en rue. On fermait les volets devant les vitrines des magasins. L'attitude impressionnante de nos hommes, et aussi la force de notre groupe, empêchèrent cependant les bandits juifs d'intervenir [...] Dans le centre-ville, nous fûmes salués avec sympathie. $^{22}$ C'était, semble-t-il, la première fois que l'A-G avait les coudées franches dans le quartier juif.

Le 31 janvier 1939, Volksverwering se rendit à Berchem où René Lambrichts, Gustaaf Vanniesbecq et Antoon Lint prirent la parole. Un

\footnotetext{
20 ARA, Archives du Parquet du Procureur du Roi d'Anvers, Brigade de la police judiciaire du Parquet d'Anvers, Versement 2001 C.

${ }^{21}$ Ibid.

22 Volksverwering, 18.12.1938, p. 2 et p. 4.
} 
autre meeting fut organisé à Berchem le 19 juillet 1939, qui réunit selon un procès-verbal de la gendarmerie, 175 personnes, dont 30 femmes. Un des orateurs était August Celis, un ouvrier diamantaire de Borgerhout. Celui-ci prit la parole sous le pseudonyme Kampers « afin de ne pas [se] faire connaître au préjudice de [sa] société et de [son] commerce ». Il était membre de l'organisation socialiste anversoise Algemeene Diamantbewerkersbond (ADB).

Volksverwering avait en effet au moins dès la fin de 1938 réussi à s'introduire dans les milieux des ouvriers diamantaires, tout comme dans les organisations des classes moyennes qui se disaient neutres, mais étaient largement favorables à l'Ordre nouveau. La direction de l'ADB n'était toutefois pas d'accord avec ses membres antisémites. Cependant, " plus de 150 ouvriers diamantaires au chômage " auraient assisté au meeting d'Anvers précédemment évoqué.

En ce qui concerne les organisations des classes moyennes "neutres", Volksverwering s'en rapprocha à la fin des années 1930 , notamment par l'intermédiaire d'Alfried (Fred) De Clopper, président de la Federatie van Wijkcomités van Antwerpen (Fédération des Comités de Quartiers d'Anvers), lui aussi un (ancien) membre du Verdinaso. Dès l'été 1939, il prêta plusieurs fois son concours à Volksverwering. Il collaborera parfois durant la même période avec Gustaaf Vanniesbecq.

Plus important encore fut le fait qu'au même moment, le Christen Middenstandsbond van Antwerpen (Union des Classes moyennes chrétiennes d'Anvers), en d'autres mots les "catholiques de parti" ("partijkatholieken"), se révéla réceptif aux prises de position de Volksverwering. La publication de l'Union des Classes moyennes chrétiennes reprit en juillet 1939 les données statistiques de Volksverwering sur la soi-disant croissance foudroyante des Juifs dans le commerce et l'industrie belges ${ }^{23}$. Mais la "question juive" fut également mise sur le tapis par le chef de file de l'Union des Classes moyennes chrétiennes d'Anvers au sein même du conseil communal anversois. En effet, le 2 août 1939, le bourgmestre socialiste anversois Camille Huysmans interdit un meeting de Volksverwering au Palais Saint-Jean (SintJanspaleis), annoncé officiellement comme une manifestation de pro-

${ }^{23}$ Het Middenstandsbelang, juillet 1939, p. 2. 
testation contre l'« invasion juive ». Lors du conseil communal, Huysmans fut immédiatement interpellé à ce propos par des représentants du VNV et de Rex, soutenus par le chef de file de l'Union des Classes moyennes chrétiennes : « Le bourgmestre a négligé le fait que c'est justement la population, que lui et nous-mêmes représentons ici, qui n’est pas d'accord avec cette décision. La question juive intéresse au plus haut degré notre population. " $^{24}$ Le journal catholique conservateur anversois La Métropole ne vit absolument aucune objection à annoncer dans ses colonnes le meeting en question.

Tout ceci n’échappa pas au consul allemand à Anvers. En juillet 1939 déjà, il écrivit avec joie à Berlin : «De plus en plus de voix au sein de la population locale s'élèvent pour exprimer leur mécontentement au sujet de l'influence juive à Anvers. „ ${ }^{25}$ Ce n'était là, semble-til, qu'un début...

\section{Le Nationaal Volksche Beweging et la montée de la violence}

Quelques semaines plus tard, Vanniesbecq démissionna de son poste de chef de la propagande de l'A-G et cessa d'être membre de Volksverwering. Nous en ignorons la raison. Presque aussitôt après cette rupture, Vanniesbecq fonda sa propre organisation, le Nationaal Volksche Beweging (Mouvement national populaire). Comme l'A-G, celui-ci avait pour symbole la rune de la Victoire (Sieg Rune) et publia à partir du 15 mars 1939 la revue De Aanval. Strijdblad voor Recht, Arbeid en Brood (L'Assaut. Journal de combat pour le droit, le travail et le pain). L'intitulé de cette revue faisait clairement référence au journal Der Angriff de Joseph Goebbels. Les caricatures provenaient de Der Stürmer. Vanniesbecq fut d'ailleurs en contact avec diverses instances allemandes. Ainsi s'adressa-t-il plus d'une fois au consulat général allemand à Anvers afin qu'on lui envoie le programme du NSDAP. Sous l'Occupation, il déclarera par exemple à un collaborateur anversois de

\footnotetext{
${ }^{24}$ Gemeenteblad Stad Antwerpen, 7.8.1939, pp. 144-149.

25 Ceges, Archives de l'Auswärtiges Amt. Politisches Archiv Bonn, Judenfrage in Belgien, 1939-1944, Courrier du Deutsches Generalkonsulat Anvers à l'Auswärtige Amt Berlin, 8.7.1939.
} 
la Sipo-SD que sa revue avait été financée par l'organisation antisémite allemande Welt-Dienst ${ }^{26}$.

Le deuxième numéro de De Aanval fut publié à 5.000 exemplaires, bien que le mouvement ne comptât vraisemblablement que quelques dizaines de partisans. Parmi eux figuraient d'anciens membres de Volksverwering comme Antoon Lint, René Bollaerts, Hubert Coppens et Richard A. Vergult. Lint devint le secrétaire de Vanniesbecq. Hubert Coppens était actif au sein du Parti ouvrier flamand nationalsocialiste (Nationaal Socialistische Vlaamsche Arbeiderspartij NSVAP), créé à Anvers en 1937. Vergult, originaire de Saint-Nicolas (province de Flandre orientale), était à l'instar de Bollaerts, Vanniesbecq et Lint, un ancien du Verdinaso ainsi que membre du Vlaams Nationaal Verbond (VNV - Ligue nationale flamande). Il fut désigné chef de propagande du Mouvement national populaire (Nationaal Volksche Beweging). Il était un familier du consulat allemand d'Anvers, où il donna plusieurs conférences. Un document allemand le décrivit comme « proallemand acharné ». C'est également par son intermédiaire qu'était financé le mouvement proallemand DeVlag. En 1939, Vergult publia les deux brochures antijuives Arbeiders-politiek en vrede (Politique ouvrière et paix) et Vrede in Europa! Hoe (La paix en Europe! Comment), dont De Aanval fit la publicité. Les publications de Vergult furent même accueillies positivement dans Boekengids. Algemeen Nederlandsch Kritisch-Bibliografisch Tijdschrift (Guide des livres. Revue bibliographique générale critique du néerlandais), une publication de l'Union anversoise des Bibliothécaires chrétiens (Antwerps Verbond van Kristelijke Bibliothecarissen) ${ }^{27}$.

Les autres membres du Nationaal Volksche Beweging avaient auparavant quasiment tous - comme Vanniesbecq, Bollaerts et Lint -, milité au sein du Verdinaso et étaient des nazis de la première heure. Parmi eux, Aloïs Goossens, qui avait été en 1935-1936 le chef faisant fonction de la section anversoise du Verdinaso. Dès 1935, il s'employa à faire de la propagande nationale-socialiste. En juillet 1937, il suivit un cours d'été au Hochschule für Politik (Université politique) à Berlin.

\footnotetext{
26 E. Verhoeyen, Spionnen aan de achterdeur. De Duitse Abwehr in België 1936-1945, Anvers, 2011, p. 381.

27 Volksgazet, « Naar de Bronnen van het Verraad. De mislukte Horst Wessel van Vlaanderen », 12.1.1945.
} 
Quelques mois auparavant, il avait créé avec deux autres Anversois l'organisation Vrienden van het Nieuwe Duitschland (VVND). Goossens rédigea son programme, pour lequel il consulta Mein Kampf d'Hitler et le programme du NSDAP. Le VVND entretint des contacts avec le Fichte Bund, la Hitlerjugend (Jeunesse hitlérienne), le Rassenpolitische Auslands-Korrespondenz ( $R A K$ - Bulletin étranger de politique raciale). Le VVND reçut par l'intermédiaire des instances allemandes de grandes quantités de matériel de propagande nazi en néerlandais, comme des discours d'Adolf Hitler, de Joseph Goebbels et d'Alfred Rosenberg. Toujours en 1937, Goossens publia Sigrunt. Kampblad der N.J. (Nederduitsche Jeugd). Vers septembre 1938, il devint chef de propagande anversois de Volksverwering. La même année, il adhéra avec son VVND au NSVAP.

Après-guerre, sa sœur décrira Goossens, à sa décharge, comme de constitution fragile depuis tout jeune, toujours plongé dans les livres et créant d'«idiots cercles de garçons », ce qui pourrait s'expliquer par des préférences sexuelles "inavouables" 28 . Après la guerre, la Volksgazet l'appelait d'ailleurs ironiquement « le Ernst Röhm de Flandre », en référence au leader homosexuel du Sturmabteilung de la NSDAP ${ }^{29}$.

L'employé Edouard Ramont était un autre membre du Nationaal Volksche Beweging. Chef du groupuscule Onpartijdig Volksverweer (Défense impartiale du Peuple), il était l'ancien éditeur responsable de De Bezem (Le Balai) (1934), qui se présentait comme « un journal de combat pour la défense des payeurs d'impôts belges en général, et en particulier des ouvriers, employés, membres de la classe moyenne, commerçants, petits propriétaires et de tous les exploitants belges ». Le chef d'action général (Algemeen Actieleider) de l'organisation était l'employé anversois et querelleur éternel Lode Welter. Il fut un temps agent de police à Anvers, mais fut licencié parce qu'il lorgnait trop les « jeunes filles du quartier du port ». Il devint ensuite, tout comme Vanniesbecq, l'ami d'Emiel Francken. Welter et Francken publièrent ensemble en 1937 Het Jodendom ontmaskerd als de aartsvijand (Le judaïsme démasqué comme l'ennemi juré), en réalité une traduction du pamphlet antisémite Les Protocoles des Sages de Sion, dans lequel les Juifs sont accusés de vouloir conquérir le monde. Toutes les organisa-

28 Auditorat militaire, Dossier Aloïs Goossens.

${ }^{29}$ De Volksgazet, 22.1.1945. 
tions antijuives et pronazies prêtaient foi aux Protocoles des Sages de Sion. De Bezem se montrait défavorable aux étrangers. Ils visaient en premier lieu les Juifs : « Nous déclarons la guerre aux Juifs ! Oui, nous sommes antisémites. » Ramont se présentait comme un déçu du Boerenbond et entretenait des liens étroits avec la Belgische Nationaal Legioen (Légion nationale belge). En 1935, il aboutit au NACO, le prédécesseur de Volksverwering, dirigé par des nationalistes belges. Le rédacteur en chef de De Stormloop (La Ruée), le journal du NACO, était d'ailleurs Lambrichts. Cette même année encore, Ramont passa au Realistische Beweging (Mouvement réaliste) de l'homme d'affaires anversois Armand Janssens, propriétaire du Century Hotel, situé près de la Gare centrale. Bien que des musiciens d'origine juive se produisaient régulièrement dans l'hôtel de Janssens, il joua bientôt de manière radicale la carte antijuive. Vers 1937, Ramont atterrit chez Volksverwering pour passer ensuite au Nationaal Volksche Beweging.

On trouvait également au sein du mouvement Jozef Vranken, un expéditeur indépendant d'Anvers, qui traduisait pour De Aanval (L'Assaut) des extraits de publications antijuives allemandes. Il était initialement actif au sein du Vlaams-nationalistische Frontpartij (Parti du Front nationaliste flamand) avant de l'être au VNV. Vers 1937, il fut séduit par le nazisme, à travers des écrits qui lui furent envoyés par les Vrienden van het Nieuwe Duitschland.

C'est vraisemblablement par le biais de Vanniesbecq que les Vrienden van het Nieuwe Duitschland reçurent les coordonnées de Vranken comme personne potentiellement intéressée. Vanniesbecq cherchait à se lier d"“amitié" avec Vranken depuis un certain temps, ayant probablement fait sa connaissance vers 1933-1934, lorsqu'il était encore membre du Verdinaso. Leur rapprochement n'avait rien d'étonnant, leurs parcours respectifs présentant de nombreuses similitudes. Tous deux avaient eu une jeunesse difficile et avaient dû apprendre très vite à se débrouiller seuls. Ils n’avaient pas achevé leurs études, mais tous deux fréquentaient les milieux nationalistes flamands et étaient passés par un bref intermezzo communiste. Ils partageaient surtout une même haine des Juifs. Comme le déclara Vranken à la justice après-guerre : «Vanniesbecq fit irruption dans ma vie par le biais du mouvement antijuif et il m’a conquis. Je ne veux évidemment pas cacher que j'éprouvais davantage de sympathie pour l'Allemagne que pour la 
France, ennemie héréditaire de la Flandre. C'est ainsi qu'on m'a fait faire le pas. $»^{30}$

Le témoignage d'après-guerre de Jozef Vranken est particulièrement intéressant. Il fut un de ces innombrables antisémites qui ne pouvaient pas donner d'explication "rationnelle" à leur haine des Juifs. Il poursuit de la sorte : «Le sentiment antijuif ne peut être expliqué. On l'a ou on ne l'a pas. Je l'ai découvert et trouvais le nouveau parti très intéressant. " $^{31}$ Vranken vit-il dans les Juifs l'équivalent négatif de son propre "sentiment d'infériorité"? Les Juifs constituaient-ils, à ses yeux, pire "racaille" - formulation dont il fait usage à son propre sujet - que lui-même ? Lorsqu'on regarde de plus près tous ces prototypes antisémites rencontrés dans la présente étude, la source principale de leur haine semble résider en grande partie dans leur histoire personnelle, le refus de l'altérité étant pour la plupart déjà bien présent dans leur jeunesse.

Et quand Gustaaf Vanniesbecq créa une section à Bruxelles, les chefs successifs de la section bruxelloise de Volksverwering, c'est-à-dire Jan De Rijcke, l'ingénieur commercial Robert Hanegreefs et le secrétaire de la section bruxelloise des Membres flamands de Volksverwering (Vlaamse leden van Volksverwering), Roger Mattheus, passèrent également au Nationaal Volksche Beweging. Tous les liens avec Volksverwering ne furent pas pour autant coupés. On fit encore de la propagande dans le premier numéro de De Aanval pour le périodique Volksverwering de René Lambrichts, ainsi que pour l'Anti-Joodsch Front d'Emiel Francken. Il semble donc que la rupture définitive avec Lambrichts advint plus tardivement.

Vanniesbecq entretenait également des relations avec François Wuyts, un marchand de grains anversois catholique, président de Hooger Op, l'Union provinciale des Meuniers, figure de proue de l'organisation des classes moyennes soi-disant "neutres" De Stormklok (Le Tocsin), créée en 1930 et, plus tard, membre du Eenheidsfront tegen de Groot-Warenhuizen Antwerpen (Front commun contre les Supermarchés à Anvers), créé en 1933. Son épouse, Yvonne Mabesoone, était tout comme son mari active au sein du Front commun contre les

30 E. Verhoeyen, België bezet. 1940-1944, Bruxelles, 1993, pp. 398-399. Note autobiographique d'après-guerre de Jozef Vranken (archives privées E. Verhoeyen). ${ }^{31}$ Ibid. 
Supermarchés et avait, à l'instar de René Lambrichts, été membre de l'organisation belgo-nationaliste Jonge Belgen (Jeunes Belges - JB), dont elle devint chef de la section pour jeunes femmes, et collaboratrice de De Nieuwe Orde, la publication "neutre" des classes moyennes. Le $1^{\text {er }}$ juin 1939, Gustaaf Vanniesbecq lança un périodique francophone, Le Combat National.

À l'instar de Volksverwering, le Nationaal Volksche Beweging disposait d'un groupe d'Action (A-G - Actie-Groep). Par ailleurs, il est probable qu'à peu près l'ensemble de l'A-G de Volksverwering soit à ce moment précis passé au Nationaal Volksche Beweging. Le Groupe d'Action ne s'opposait absolument pas à l'usage de la violence. Une fois de plus, le parc municipal "grouillant" de Juifs monopolisant les bancs publics suscita l'indignation : «On en a déjà jeté quelques-uns à l'eau, mais elle n'était pas assez profonde et le lendemain, les mêmes gaillards étaient déjà de retour. $»^{32}$

La plupart des objectifs du Nationaal Volksche Beweging étaient les mêmes que ceux du Verdinaso, mais s'y s'ajoutaient des éléments explicitement racistes et antijuifs. Le Nationaal Volksche Beweging reprochait d'ailleurs au Verdinaso d'être trop laxiste à l'encontre des Juifs. Là aussi, la violence était au rendez-vous. De Aanval explique : « Il y a quelques jours, environ cinq autobus chargés de membres du Verdinaso s'arrêtèrent au milieu du quartier juif près de la rue de la Couronne. À la question sur ce qu'ils venaient y faire, un blagueur répondit qu'ils venaient tuer tous les Juifs et qu'ensuite ils jetteraient tous leurs biens au feu. Il ne s'agissait malheureusement que d'une blague, car c'était bien des membres du Verdinaso... et ceux-ci ne font rien de contraire à la loi... ${ }^{33}$ La provocation des membres du Verdinaso dans le quartier juif anversois n'était pour De Aanval apparemment pas suffisante et le journal ne mentionnait pas le fait qu'en cette période le Verdinaso organisait à Anvers d'innombrables meetings antijuifs.

Le Nationaal Volksche Beweging souhaitait également organiser les 20 et 24 juillet 1939 des meetings à Berchem, dans la salle Rubens de la rue de la Station, qui auraient pour thèmes La Belgique, champ de bataille de l'Europe et poubelle du monde et Le Juif Gutt, Ministre des fi-

32 De Aanval, 15.6.1939, pp. 2-3.

${ }^{33}$ Ibid. 
nances et dictateur de la Belgique. Toutefois, le collège communal (constitué d'une coalition de catholiques et de socialistes) en interdit la tenue, car «le sujet qui sera traité lors de ces meetings tout comme les affiches apposées le long de la voie publique peuvent donner lieu à des perturbations et des désordres ». Dès lors qu'ils étaient susceptibles de déranger l'ordre public, ces meetings étaient interdits. La police reçut l'ordre d'enlever les affiches. Après que Gustaaf Vanniesbecq en fut informé, une certaine Aktie ter Verdediging van Handel en Arbeid tegen Vreemde Inmenging (Action pour la Défense du Commerce et du Travail contre l'Ingérence étrangère) introduisit une demande d'autorisation pour organiser un meeting. Le requérant n'était autre qu'Antoon Lint. Bien que le bourgmestre catholique Walter Colignon eut donné son feu vert, le meeting fut finalement interdit suite à une séance communale houleuse.

En août 1939, Vanniesbecq fut un des hommes à l'origine des émeutes antijuives dans le quartier de la gare d'Anvers - émeutes initialement soutenues par à peu près l'ensemble de la presse anversoise catholique et gagnée à l'Ordre nouveau. L'inquiétude face à une guerre imminente et le mécontentement grandissant quant à la présence juive avaient atteint à Anvers un point de cristallisation. Le 25 août 1939, le gouvernement décréta pour la seconde fois la mobilisation. Dans le cadre de l'état d'urgence, il décida en outre d'avancer l'heure de fermeture des auberges et débits de boisson. Cette initiative eut pour seul effet de déverser dans les rues davantage de personnes "contrariées".

Lorsqu'il s'avéra qu'un débit de boisson de l'avenue De Keyser (De Keyserlei) n'avait pas fermé ses portes à l'heure fixée, l'explication en fut toute trouvée : les exploitants étaient juifs! Rapidement retentirent les « Ouste les Juifs! », les « Nos gens doivent fermer et les Juifs peuvent continuer ». On en vint à des voies de fait et la police dut « charger plus d'une fois ${ }^{34}$.

Les premières émeutes pouvaient probablement encore être considérées comme "spontanées". Mais lorsqu'elles se poursuivirent le lendemain, samedi, à 22 heures, il était évident que des provocateurs étaient de la partie. "Un groupe de manifestants, hommes et femmes, fort d'environ 100 personnes, traversa le quartier en hurlant des slo-

\footnotetext{
${ }^{34}$ De Volksgazet, 26.8.1939, p. 5.
} 
gans antijuifs. La police tenta de calmer les gens et de les faire rentrer chez eux paisiblement. ${ }^{35}$ Ces tentatives échouèrent. La police ne put empêcher « que d'autres petits groupes se formèrent à nouveau » et, à un certain moment, une vitrine d'un commerce juif de la rue du Pélican (Pelikaanstraat) vola en éclat. Le calme revint vers minuit, même si une vitre de la synagogue de la rue d'Orient (Oostenstraat) fut encore brisée, plus tard dans la nuit ${ }^{36}$.

Bien que ces troubles eurent vraisemblablement été le fait d'une bande de voyous, composée d'hommes et de femmes, l'ensemble de la presse (néerlandophone) anversoise catholique les trouva justifiés. La presse socialiste et libérale n'emboîta pas le pas aux catholiques. Selon la Gazet van Antwerpen, journal catholique, il s'agissait d'une "action spontanée" et "l'indignation des braves Anversois » envers les Juifs était « légitime ». Quatre jours auparavant, le journal avait même encore critiqué «le grand afflux d'étrangers » et terminait par ces mots : «Les Anversois de souche (sinjoren) se montrent provisoirement accueillants et tolérants, mais la patience a des limites... ${ }^{37}$ Le journal catholique Handelsblad van Antwerpen titra Relletjes! Tegen de aanstellerij van de Joden (Émeutes! Contre la cuistrerie des Juifs !). À la page précédente, le journal se prononçait pour la fermeture des frontières et assimilait tous les réfugiés à de la « racaille » communiste : « Notre public est déjà assez énervé face à ce surplus d'étrangers, que ce serait un scandale d'en laisser entrer plus. $»^{38}$ Pour le journal catholique $D e$ Morgenpost, il était tout aussi clair que la raison des émeutes devait être recherchée dans l'attitude même des Juifs : « Des commerces juifs de la Keyserlei et d'autres lieux du centre-ville ne se soucièrent simplement pas de l'interdiction et maintinrent ouvert leur débit de boisson. » Le sous-titre était tout aussi éloquent : « À Anvers, des manifestations antijuives provoquées par des Juifs. $»^{39}$

Le bureau de l'Auslandsdienst (Service étranger) allemand à Bruxelles était extrêmement satisfait. Dans son rapport sur la situation en Belgique, il est fait référence « aux nombreux incidents violents

\footnotetext{
35 La Métropole, 27.8.1939, pp. 4-5.

36 Ibid.

${ }^{37}$ Gazet van Antwerpen, 21.8.1939, p. 4 ; 26.8.1939, p. 1 ; 27.8.1939, p. 7.

38 Het Handelsblad van Antwerpen, 27.8.1939, pp.2-3.

${ }^{39}$ De Morgenpost, 26.8.1939, p. 3.
} 
contre les Juifs et les commerces juifs à Anvers » : "On y a démoli des boutiques et donné l'assaut à des locaux juifs. »" Même le consul italien à Anvers jugea nécessaire de faire rapport des émeutes à ses supérieurs à Rome et signala le mécontentement croissant « à l'encontre des Juifs » à Anvers ${ }^{41}$.

Quelques mois auparavant, en mai 1939, la Vlaamsche Conferentie der Balie van Antwerpen (Conférence flamande du Barreau d'Anvers), un cercle constitué d'avocats anversois, avait exclu tous les confrères juifs. Une décision qu'avait soutenue entre autres Maurits Langhor, un avocat catholique, qui avait étudié en Allemagne. En mai 1937, il avait donné pour Volksverwering une conférence intitulée « Le national-socialisme et le judaïsme » (« Nationaal socialisme en Jodendom »). Il était, selon toute probabilité, également membre de Volksverwering. Il figurait sur la liste VNV d'Anvers comme représentant du groupe Ontevreden katholieke Vlamingen (Catholiques flamands mécontents) lors des élections communales d'octobre 1938.

À la même époque, Bollaerts et Vanniesbecq effectuèrent probablement des missions d'espionnage pour l'Abwehr. Pendant la guerre, ce dernier déclara à un membre anversois de la Sipo-SD que, quelques mois avant l'invasion allemande, il avait effectué des missions d'espionnage au port d'Anvers ${ }^{42}$.

Entretemps, René Bollaerts était également devenu membre de l'organisation nazie semi-clandestine De Adelaar (L'Aigle), créée en 1938, qui comptait différents (futurs) membres de l'Abwehr. Les membres de De Adelaar - qui n'étaient probablement pas plus d'une dizaine - étaient encouragés à rassembler des données relatives aux locaux communistes et juifs à Anvers et ses alentours, à repérer dans les usines les communistes et les socialistes, les produits inflammables dans les ports et à répertorier cloîtres, temples, synagogues, tunnels, ponts, passages à niveau, barrages routiers, casernes, dépôts militaires, etc. L'utilisation de ces listes, selon l'historien Etienne Verhoeyen, n'est pas claire: étaient-elles destinées à un usage personnel (par exemple après une invasion allemande) ou devaient-elles être trans-

\footnotetext{
${ }^{40}$ Ceges, Archives Osoby Moscou, Rapport Auslandsdienst Brussel, 2.9.1939.

41 A. Morelli, « Les diplomates italiens en Belgique et la "question juive" », 1938-1943, dans Bulletin de l'Institut historique belge de Rome, 53-54, p. 375.

${ }^{42}$ E. Verhoeyen, Spionnen..., op. cit, p. 210.
} 
mises à un service allemand ${ }^{43}$ ? En outre, Bollaerts fut nommé membre d'Hercules, une sorte de "cinquième colonne", qui transmettait des rapports relatifs à des questions militaires à l'Abwehr. Les membres d'Hercules devaient par exemple sillonner la Belgique selon un parcours déterminé afin d'enregistrer des données relatives à l'état des routes, aux contrôles de celles-ci et à tout ce qui concernait la défense belge. Selon un témoignage allemand d'après-guerre, Bollaerts mit à cet effet son camion, un Diamond $T$ américain, à disposition ${ }^{44}$.

Par arrêté ministériel du 12 mars 1940, les publications du Nationaal Volksche Beweging et de Volksverwering furent interdites.

\section{Autres organisations nazies et antisémites : le phénomène anversois}

On l'a vu, Anvers hébergea les différentes organisations évoquées (Volksverwering, Vrienden van het Nieuwe Duitschland, NSVAP, De Adelaar, Anti-Joodsch Front, Dietsche Arbeiderspartij et Nationaal Volksche Beweging), créées dans les années 1930. Elle peut donc véritablement être considérée comme le berceau des organisations nazies et antisémites. D'ailleurs, dès la fin des années 1920, des initiatives similaires y avaient vu le jour. 1929 fut une année charnière dans les milieux nationalistes flamands : l'admiration suscitée par le nazisme impliqua un rapprochement entre les milieux racistes allemands d'extrême droite et les nationalistes flamands. Dès cette année, le Verein Deutscher Studenten, une organisation estudiantine allemande en phase de nazification croissante, proposa des bourses d'études pour universitaires étrangers. Les futurs créateurs et dirigeants de l'Algemeene SS-Vlaanderen se trouvaient parmi les invités. De surcroît, en 1929, le gouvernement belge promulgua une loi autorisant les collaborateurs de la Première Guerre mondiale ayant fui en Allemagne à rentrer en Belgique. Ces collaborateurs seront les premiers à être en contact avec le national-socialisme.

En 1929, fut créé à Anvers le périodique Vrij Leven. Maandblad voor Lichaamscultuur, Openlucht-Leven en Vrije Levensvorming (Vivre librement. Mensuel pour la culture du corps, la vie au grand air et les formes de vie libres). Sous un titre apparemment innocent se cachait

\footnotetext{
43 Ibid., p. 184.

${ }^{44}$ Ibid., p. 297 et p. 356.
} 
une publication à laquelle contribuèrent les premiers adeptes du nazisme flamand.

Vrij Leven était en fait la voix de la Vlaamse Kampeergemeenschap (VKG - Communauté des Campeurs flamands) et fut suivi de Naar Bosch en Hei (Vers les bois et les landes, 1930-1931). Certes, il y avait au sein de VKG une minorité de gauche, mais l'extrême droite, majoritairement laïque, y était largement dominante. On trouvait dans les pages de la publication du VKG, outre la promotion du nudisme, de la marche, du camping, de l'abstinence et du végétarisme, un discours antiparlementaire empreint de la symbolique du svastika, de mystique germanique, de racisme et d'antisémitisme virulent. Les danses folkloriques germaniques étaient également fort prisées. On retrouvera plus tard la plupart des membres du VKG au NSVAP, qui regroupait différents groupuscules nationaux-socialistes.

Le mouvement de jeunesse "neutre" anversois Wunihild, rebaptisé Oranje Jeugd-Bond (OJB) en 1932, était affilié au VKG. Il distribuait de la lecture nazie, des discours d'Adolphe Hitler et des idéologues Joseph Goebbels et Alfred Rosenberg, ainsi que des svastikas livrés par le NSDAP-Verlag Paul Arndt. Il avait en outre des contacts avec le Fichte Bund, le Welt-Dienst, la Hitlerjugend, le RAK (Rassenpolitische Auslands-Korrespondenz) et le Heimattreue Front, organisation politique rassemblant des Allemands des Cantons de l'Est, visant au rattachement au Reich.

Le NSVAP, organisé une première fois en 1937 et de nouveau en 1938, était l'héritier direct de la Germaansche Gilde (Guilde germanique), qui vit le jour en 1936, le premier groupuscule nationalsocialiste d'une certaine envergure dans la région anversoise et même en Belgique. La Germaansche Gilde choisit pour emblème la Hagalrune, qui, avec un certain sens du pathétique et de la mystique, fut décrite comme « le symbole de la noble race nordique et l'emblème de la Sagesse secrète des savants Germaniques ». Le premier numéro du périodique de la Germaansche Gilde annonçait immédiatement la couleur avec la devise « Les Juifs sont notre malheur! », qui était également celle du journal diffamatoire antisémite allemand Der Stürmer.

Vers mai 1937, l'année qui vit aussi la création de Volksverwering, la Germaansche Gilde fut rejointe par les Vrienden van het Nieuwe Duitschland. La même année fut créé la Nederduitsche Hitlerjeugd 
(NHJ), qui fut rebaptisée Nederduitsche Jeugd (NJ). Un an plus tard, furent créés, outre De Adelaar et le Anti-Joodsch Front, le Vlaamsche Arbeiderspartij (VAP), le Dietsche Arbeiderspartij (DAP) et le Nationaal Socialistische Centrale (NSC). En mai 1940, peu avant l'invasion allemande de la Belgique, ce fut au tour de l'asbl Hulp voor Oorlogsslachtoffers (Aide aux Victimes de Guerre). Si la dénomination semblait alors innocente, il s'agissait en réalité d'une organisation coupole nationale-socialiste, créée à l'initiative d'anciens membres anversois de la VKG.

Les organisations susmentionnées ne rassemblaient probablement pas plus que quelques centaines de militants actifs. Le NSVAP aurait compté environ 500 membres, parmi lesquels la majorité était constituée d'Anversois d'extraction modeste ${ }^{45}$. D'un tout autre ordre fut le Dietsche Opvoedkundige Beweging (DOB - Mouvement éducatif thiois), créé à Anvers en juillet 1937 sous l'impulsion de quelques jeunes enseignants laïcs et d'élèves d'Écoles normales. Tous étaient d'anciens élèves de l'école normale de la Ville d'Anvers. À l'instar des Vrienden van het Nieuwe Duitschland, DOB plaida pour « une philosophie germano-thioise », avec comme principes de base la « race », le « sol» et l'«honneur et la fidélité ». Convaincus que le «peuple thiois » appartient à la « race nordique », ils s'opposaient au « mélange racial ». Les Juifs étaient décrits comme des «poux étrangers », des « nez crochus », incapables de " génie créateur » et comme les « ennemis les plus inconciliables » de la « communauté populaire thioise», qui s'en prenaient particulièrement à la jeunesse ${ }^{46}$.

En décembre 1937, DOB s'allia au Dietsch Front (fraîchement créé, mais qui était en réalité la nouvelle appellation de la Germaansche Gilde). Après un mois à peine, s'annonça la fin de cette collaboration. Le DOB entretint néanmoins des contacts intenses et de longue durée avec Volksverwering - des contacts qui se prolongeront jusque sous l'Occupation.

L'analyse des parcours individuels et des organisations montre que sympathie nazie et antisémitisme étaient avant tout un phénomène anversois. Pareils ensembles réussissaient avec peine à s'imposer à

45 Volksgazet, « Naar de Bronnen van het Verraad. De leerrijke Historie van de N.S.V.A.P. », 22.1.1945.

${ }^{46}$ Dietsch Opvoedkundig Tijdschrift, 1, 1939, pp. 1-7; 2, p. 29 ; 4, pp. 57-60 ; 6, p. 89. 
Bruxelles. Quand en juin 1938 fut publiée une édition française de Volksverwering, le tirage en était limité. En outre, contrairement à son pendant flamand, l'édition française parut en version stencil et compta peu d'abonnés : en mars 1938, il y en avait sept, et 249 en décembre 193947. Ce ne fut qu'à partir d'octobre 1938 que la section bruxelloise de Volksverwering disposa d'un secrétariat propre, situé dans la rue Fossé-aux-Loups, près de la Monnaie. Et lorsque le 12 juillet de cette même année, une première «réunion de recrutement » eut lieu à Bruxelles, ce furent des membres du Groupe d'Action anversois qui, sous la houlette de Gustaaf Vanniesbecq, durent en maintenir 1"“ordre". En avril 1939, René Lambrichts reconnaissait qu'«à Bruxelles, on cherche de nouveaux propagandistes, car les plus anciens sont à bout de force $~^{48}$.

Il faut noter que la pensée antijuive ne plongeait pas ses racines dans le nationalisme flamand mais bien dans le nationalisme belge. Dans les années 1920 déjà, le nationalisme belge choisit clairement la voie antijuive, tout en se distanciant de l'antisémitisme biologique de l'Allemagne nazie, et ce à l'inverse du Verdinaso et du VKG. Pour les nationalistes belges, l'Allemagne demeurait le pays des "casques à pointe", qui avait commis des atrocités en Belgique pendant la Première Guerre mondiale et l'avait pillée. Le foyer nazi anversois constituait en cela une exception : les nationalistes belges et les affidés nazis nationalistes flamands s'allièrent autour de l'antisémitisme, comme l'illustre l'exemple de Volksverwering. Certains membres de la Nationaal Legioen (Légion nationale), de tendance nationaliste belge, iront même jusqu'à collaborer avec le NSVAP. Et, quand en 1939, les réfugiés juifs du paquebot Saint-Louis arrivèrent à Anvers, la Nationaal Legioen distribua un pamphlet signé René Lambrichts, leader de Volksverwering. Les Juifs y étaient décrits comme des « rapaces », dans ces mots choquants : "Ils pillent, volent et trahissent, empestent notre ville et nous ruinent. [...] La Jeune Garde nationaliste (Nationalistische Jonge Wacht) veut vous aider, Juifs! Il y a de solides cordes

\footnotetext{
47 ARA, Archives du Parquet du Procureur du Roi d'Anvers, Archives de la brigade de la police judiciaire du Parquet d'Anvers, Versement $2001 \mathrm{C}$.

48 Volksverwering, 9.4.1939, p. 4.
} 
avec des crampons au 24 de la rue des Frères mineurs [le local du parti de la Légion nationale anversoise, ndla] $»^{49}$.

\section{La Seconde Guerre mondiale : déportation et collaboration}

Que René Bollaerts et Gustaaf Vanniesbecq aient été arrêtés en tant que "suspects" en mai 1940 n'a rien d'étonnant. Comme beaucoup d'individus cités plus haut (Aloïs Goossens, Hubert Coppens, René Lambrichts, Ward Hermans et René Lagrou), Vanniesbecq est déporté vers le camp de Saint-Cyprien/Le Vernet d'Ariège dans le sud de la France.

Or des milliers de Juifs arrêtés se retrouvèrent également à SaintCyprien/Le Vernet d'Ariège, ce qui donne lieu à des situations curieuses. Ainsi, dans une même baraque, la $n^{\circ} 37$, s'étaient rassemblés des Juifs anversois avec leur rabbin et... Gustaaf Vanniesbecq, René Lambrichts et Ward Hermans. Dans la période juillet-août 1940, après la capitulation de la France, les "suspects" affidés de l'Ordre nouveau furent libérés.

À leur retour, ces suspects gagnés à l'Ordre nouveau s'engagent dans la collaboration. Plusieurs d'entre eux relateront leurs aventures comme "suspects" dans des livres. Dans aucun de ces écrits, par exemple ceux de Ward Hermans et René Lagrou, on ne trouve une once de compassion pour leurs compagnons d'infortune juifs - qui, sur ordre des Allemands, ne recouvreront d'ailleurs pas la liberté.

Pour l'une ou l'autre raison, René Bollaerts ne fut pas déporté comme "suspect". Libéré de la prison d'Anvers de la rue des Béguines le 17 mai, il s'engagea presque immédiatement - avant même la capitulation belge - auprès des Brandenburgers (Baulehrkompanien zur Besonderen Verwendung), une troupe commando allemande de la Wehrmacht ouverte aux non-Allemands. Après une formation à la Körnerkazerne à Aix-la-Chapelle, à Orléans et à La Celle-Saint-Cloud, en France, il fut incorporé d'octobre au 23 décembre 1940 au Sonderstab Hollman à Oostduinkerke, dans l'attente d'une offensive sur

${ }^{49}$ G. Meulenaer - L. Walleyn, « De Jodenvervolging in België », dans A. Martens - L. Walleyn - V. Hobin - G. Muelenaer (Éds.), Verdeel en heers. Racisme als strategie, Berchem, 1982, p. 14 ; Volksverwering, 30.6.1939. 
l'Angleterre ${ }^{50}$. C'est à présent en tant que Brandenburger que Bollaerts se mit à nouveau au service du groupe Hercules, qui lui assigna des missions de sabotage.

Emiel Francken de l'Anti-Joodsch Front (Front antijuif) fut également arrêté comme "suspect" le 10 mai 1940. Mais, pour des raisons demeurées obscures, il fut immédiatement libéré par la police.

À son retour du Vernet, le 9 août 1940, Vanniesbecq se fit, à l'instar de Robert Hanegreefs, son compagnon au sein du Nationaal Volksche Beweging, membre du NSVAP (Nationaal-Socialistische Vlaamsche Arbeiderspartij). Des groupuscules nationaux-socialistes tels que la Nederduitsche Jeugd, le Vlaamsche Arbeiderspartij, les Vrienden van het Nieuwe Duitschland et De Adelaar furent alors intégrés au NSVAP.

Vanniesbecq prit presque immédiatement contact avec Francken de l'Anti-Joodsch Front : « Il est temps à présent de se réunir et de rester ensemble. C'est dans cet esprit-là que j'ai à vous faire part de l'une ou l'autre chose. „ On ignore du reste le contenu factuel de leur conversation, si conversation il y eut. Il s'agissait probablement du lancement d'un journal antijuif, pour lequel Vanniesbecq aurait obtenu le soutien du SS-Hauptsturmführer Dr Perey, attaché à la Sipo-SD de Bruxelles.

Ce journal antijuif ne verra finalement pas le jour. Les dirigeants de la Sipo-SD de l'avenue Louise à Bruxelles y mirent en effet le holà. Même pour la Sipo-SD Dienststelle Bruxelles, s'associer à une figure incontrôlable comme Vanniesbecq était trop risqué. L'auteur du rapport de la Sipo-SD remarqua : «[Vanniesbecq] a selon mes informations déjà eu souvent maille à partir avec la Justice [...]. Dans les milieux politiques, il est de notoriété publique qu'il s'est mêlé à divers mouvements politiques, mais y a toujours semé la discorde et fut exclu des associations. [...] D'après d'autres informations, il se serait très mal comporté dans le camp d'internement du Vernet. L'opinion générale à son sujet est qu'il agit de façon irréfléchie et irresponsable et qu'il n'est pas une personnalité irréprochable. $»^{51}$

\footnotetext{
50 E. Verhoeyen, Spionnen..., op. cit., p. 356.

51 Auditorat militaire, Dossier Volksverwering, Courrier Sipo-SD, NSDAP, Ortsgruppe Anvers et Reichsicherheitshauptamt concernant Jozef Baeten, Gustaaf Vanniesbecq et René Lambrichts, 10 mai - 19 août 1941.
} 
Jozef Baeten, qui avait soutenu financièrement Volksverwering, se brouilla également avec Lambrichts. Tout comme Vanniesbecq, il était membre de l'Algemeene SS-Vlaanderen. Dès le début de l'Occupation, il devint le représentant du Deutsche Schmalfilm für Belgien. Comme Vanniesbecq, afin de s'arroger le pouvoir de posséder un journal antijuif, il déposa une plainte auprès des Allemands contre Lambrichts. Il sembla tout d'abord obtenir gain de cause, la Propaganda-Abteilung Belgien lui donnant l'autorisation pour la «publication d'un périodique antijuif », mais la Sipo-SD de Bruxelles intervint de nouveau. Son jugement à propos de Baeten était tout aussi accablant que celui concernant Vanniesbecq ${ }^{52}$.

Gustaaf Vanniesbecq put finalement travailler comme entrepreneur à l'aérodrome de Deurne vers février-mars 1941. Il fit notamment fabriquer des filets de camouflage pour la Wehrmacht et se chargea du transport de matériel pour la construction d'aérodromes dans toute la Belgique et jusque dans le nord de la France. Les aérodromes constituaient des opportunités d'emploi appréciées. Vanniesbecq vendait également des chevaux et des camions. Quasiment sans le sou avantguerre, Vanniesbecq construisit sous l'Occupation un petit empire financier. Souvent ivre mort, il dépensait une fortune en repas et boissons, notamment dans l'hôtel-restaurant L'Industrie situé rue du Pélican (Pelikaanstraat), où il invitait des membres de la Gestapo et de la Wehrmacht. Il entretenait, outre son épouse, une maîtresse. En revanche, il ne payait qu'une partie des salaires de ses employés, leur disant qu'ils n'avaient qu'à encaisser le reste à la Wehrmacht. Personne n'osait protester.

Outre le fait d'adhérer à la SS, Gustaaf Vanniesbecq travaillait pour la Geheime Feldpolizei et le Sicherheitsdienst et fut désigné SSRottenleiter en novembre 1942.

Il faut noter l'opposition politique avec son père, Antoine Vanniesbecq, qui entra dans la Résistance. En juillet 1941, il fut emprisonné par les autorités d'occupation pour avoir publié et diffusé des imprimés non autorisés. Il fut d'abord emprisonné trois mois à la prison de Saint-Gilles, puis interné à Merksplas. Pendant sa détention à Merks-

52 Ceges, Archives E. Francken, Courrier de G. Vanniesbecq à E. Francken, août 1940 ; M. De Wilde et E. Verhoeyen, De Kollaboratie. België en de Tweede Wereldoorlog, 5, Anvers-Amsterdam, 1985, p. 100. 
plas, il échafauda le projet de créer un « mouvement national humanitaire gallo-wallon ». Après sa libération, le 31 octobre 1942, il rejoignit les rangs de la résistance communiste. Il aurait recouvré la liberté grâce à l'intervention du catholique Gaston Schuind, secrétaire général du ministère de la Justice ${ }^{53}$.

Depuis début 1941, René Bollaerts travaillait comme chauffeur à l'aérodrome de Deurne, ainsi qu'à celui de Melsbroek. La même année, le 5 octobre 1941, il adhéra comme Vanniesbecq aux Algemeene SSVlaanderen. À partir de mars 1942, il s'adonna un temps à la contrebande. Vers le mois d'août de cette année, Otto Desselmann, qui était à la tête du Sicherheitsdienst (SD) anversois, l'appela pour participer à des rafles de Juifs.

Antoon Lint devint également membre de l'Algemeen SSVlaanderen. Il gagna Liège où il devint Stormleider du SS-Stormban Liège, chef du Service social et chef de la cellule liégeoise de DeVlag ${ }^{54}$. Il y mit en place la section locale de Volksverwering et devint Vertrauensmann (V-man) de l'Abwehr de Liège. Durant l'été 1941, il suivit une formation à la Waffen-SS-Vorschule à Schoten, dans la banlieue anversoise où, en 1943, il participa également à l'Unterführerlehrgang. Vers la Libération, en septembre 1944, il s'engagea auprès de Jagdverband 502, un corps d'élite SS du SS-Standartenführer Otto Skorzeny, qui avait libéré Benito Mussolini en septembre 1943.

Antoon Lint ne fut pas le seul Anversois actif en Wallonie sous l'Occupation. Ce fut par exemple également le cas de Jozef Vranken, qui y dirigea une section de l'Abwehr. Ce fut une fois de plus Gustaaf Vanniesbecq qui introduisit Vranken auprès de l'Abwehr. Après son retour de Saint-Cyprien, Vanniesbecq invita Vranken, sans emploi comme expéditeur du fait de la guerre, au café Malpertuus, le local VNV à Anvers. C'est là qu'il lui présenta un espion allemand de l'Abwehr, qui avait chargé Vanniesbecq de recruter des agents. Vranken fut un "bon choix". Tout au long de l'Occupation, son équipe sera à l'origine de l'arrestation de 150 personnes, dont 40 décéderont. Vranken devint en même temps membre de DeVlag. Son bras droit à

\footnotetext{
53 Service public fédéral Securité sociale, Service des Victimes de Guerre (SVG), Dossier d'Antoine Vanniesbecq.

54 E. De Bruyne, « Moi Führer des wallons! ». Léon Degrelle et la collaboration outreRhin, Liège, 2012.
} 
l'Abwehr était Constant Van Dessel, recommandé par Vanniesbecq. Vranken aura finalement au moins 32 morts sur la conscience.

Tous les compagnons d'avant-guerre de Gustaaf Vanniesbecq, tels Aloïs Goossens, Robert Hanegreefs, ou Ward Hermans, s'engagèrent sur la voie de la collaboration.

Vers fin août - début septembre 1940, Aloïs Goossens était à la tête de la Section politique du NSVAP, dont Vanniesbecq, ainsi que Robert Hanegreefs, étaient membres. Du fait d'un différend personnel avec René Lagrou, qui avait, entre autres, découvert l'homosexualité de Goossens, celui-ci ne pouvait plus aspirer à jouer un rôle de premier plan dans les rangs de la collaboration.

Le 10 août 1942, en pleine période de déportation, fut conclu un accord de collaboration entre Volksverwering et le Dietsche Opvoedkundige Beweging (DOB). «Vu que le combat antijuif est inextricablement lié à la rééducation de notre communauté populaire, nous avons jugé nécessaire d'entériner officiellement la collaboration des deux groupes », précisa DOB ${ }^{55}$.

À partir de l'été 1942, Vanniesbecq et Bollaerts se révélèrent des chasseurs de Juifs des plus motivés. Il s'agissait pour Vanniesbecq d'une "activité d'appoint", et pour Bollaerts, de son "activité principale". Mais avant tout cela, il y eut encore la "Kristallnacht" anversoise.

\section{Le lundi de Pâques du 14 avril 1941 : une "Kristallnacht" anversoise}

Dans la matinée du dimanche 6 avril 1941, l'organisation antijuive Volksverwering programma au cinéma Rex, situé sur la De Keyserlei, la projection du film antisémite Der Ewige Jude ("Le Juif éternel") du réalisateur allemand Fritz Hippler. Les Juifs y étaient dépeints comme des rats porteurs de bacilles et des sous-hommes. C'est René Lambrichts, le leader de Volksverwering, qui introduisit le film. Vu «l'écrasant succès » de la première représentation, le film fut projeté une seconde fois le lundi de Pâques 14 avril $^{56}$. Devant une salle comble, Lambrichts introduisit de nouveau le film. Quelques semaines aupara-

55 Dietsch Opvoedkundig Tijdschrift, «Samenwerking tusschen Volksverwering en DOB », août-septembre 1942, p. 168.

56 Volk en Staat, 9.4.1941. 
vant, le 26 mars, il avait participé à Francfort à l'ouverture officielle de l'Institut zur Erforschung der Judenfrage (Institut pour l'étude de la question juive), sous les auspices de l'idéologue nazi Alfred Rosenberg. Vanniesbecq et Reimond Tollenaere, le dirigeant de la propagande VNV, étaient également présents. Au terme de la projection du film, vers midi trente, une partie des spectateurs et 200 à 400 membres de Volksverwering, de l'Algemeene SS-Vlaanderen et de De Zwarte Brigade (la milice du VNV), armés de bâtons et de barres de fer, se livrèrent à des actes de vandalisme. Une photo de l'événement nous apprend qu'un certain nombre de femmes comptaient parmi les émeutiers. On les voit poser fièrement avec leurs comparses masculins près d'un drapeau en velours noir sur lequel on peut lire «Juda Verrecke » (« Crève, Juif ») et «Ras en Bodem » (« La race et le sol »). Des militaires allemands participèrent également à l'action. Les Allemands semblaient avoir été prévenus : la présence d'une équipe de tournage allemande sur les lieux n'est probablement pas due au hasard. Ce pogrom "spontané" avait été en fait soigneusement préparé, sans doute par Vanniesbecq, car c'est son comparse Piet Verhoeven qui orchestra le tout. Cet architecte anversois, fils d'un menuisier catholique aisé, avait avant même la guerre un lourd casier judiciaire, comme Vanniesbecq. Sous l'Occupation, comme Vanniesbecq, il travailla pour la Wehrmacht, se chargeant de livraisons pour l'aérodrome de Deurne. D'abord membre du VNV, il adhéra en 1941 à l'Algemeene SSVlaanderen et à DeVlag. Comme Vanniesbecq, il travailla pendant presque toute l'Occupation pour la Geheime Feldpolizei et le Sicherheitsdienst, ainsi que pour le Devisenschutzkommando, le service allemand chargé de la spoliation des biens juifs. Il deviendra également un SS chasseur de Juifs. Dans le quartier juif, plusieurs vitres de maisons furent brisées et des devantures abîmées. À la synagogue de l'avenue Van Den Nest (Van den Nestlei), les grilles furent arrachées, le mobilier détruit, les fenêtres brisées, des livres sacrés déchirés et jetés dans la rue puis incendiés « ensemble avec d'autres affaires appartenant au culte juif $\aleph^{57}$. Des foyers d'incendie furent également allumés dans la

\footnotetext{
57 FelixArchief, MA, Dossier $\mathbf{n}^{\circ}$ 3221, Recueil 89, Procès-verbaux des commissaires de police adjoints de la 7 e section $H$. Van Linden et F. Vandenblunder, 14.4. 1941 ; Rapports du major des pompiers E. Van Cappellen, 15 et 25.4.1941. Voir également : FelixArchief, MA, $\mathbf{n}^{\circ}$ 29051, Rapports officiers 6e section, 30.4.1941 ; FelixArchief,
} 
synagogue. La synagogue et la maison du rabbin Marcus Rottenberg dans la rue de l'Orient (Oostenstraat) furent aussi vandalisées. Comme cela était prévisible, la Ville d'Anvers refusa d'indemniser les victimes juives après les faits.

\section{Le rôle des autorités dans la "chasse aux Juifs"}

On ne peut en effet faire l'impasse sur le rôle joué par les autorités de la ville et de la province d'Anvers, par l'administration locale, par les policiers, les instances judiciaires et le barreau dans cette traque. Ce ne fut pas de leur propre initiative que ces instances participèrent à la persécution des Juifs, mais c'est toujours loyalement qu'elles exécutèrent les ordonnances allemandes. Nous savons qu'en août 1942, c'est la police anversoise qui assista en premier les Allemands dans la poursuite des Juifs. Ce fut ensuite le tour du Stormban anversois des SS flamands.

La collaboration de la police anversoise aux rafles se situe dans le droit fil de ce qui s'était passé antérieurement. Presque d'emblée, les Allemands purent s'assurer de cette collaboration. Les termes « agression cumulative », repris dans certains ouvrages spécialisés - entre autres dans ceux de l'historien britannique Ian Kershaw - correspondent parfaitement à l'intervention des policiers anversois ${ }^{58}$. En effet, en décembre 1940, la Feldkommandantur décida d'expulser des milliers de Juifs vers le Limbourg et la police anversoise leur distribua 8.609 formulaires de réquisition. Le 23 décembre, la police anversoise reçut l'ordre écrit de la Feldkommandantur d'arrêter les Juifs qui ne s'étaient pas présentés. Le bourgmestre, le procureur du Roi et le commissaire en chef de la police se consultèrent et décidèrent de prêter leur concours à l'arrestation des réfractaires. Le 25 décembre, le commissaire en chef écrivit au procureur du Roi que le local de la rue Van Diepenbeeck (un ancien magasin de lits de l'armée belge) serait utilisé comme lieu de rassemblement pour les Juifs arrêtés. Un mois plus tard, en janvier 1941, les forces de l'ordre de la ville escortaient les personnes convoquées jusqu’à leur départ en train pour le Limbourg. Quelques

MA, $\mathbf{n}^{\circ}$ 28080, Procès-verbaux 6e section, avril-mai 1941 (pv $\mathbf{n}^{\mathrm{os}} 1315,1318,1323$, 1631).

${ }^{58}$ I. Kershaw, Hitler, Tome I et II, Londres, 1998 et 2000. 
jours plus tard, la police était disposée à aller chercher chez eux les "Juifs du Limbourg" qui n'avaient pas donné suite à l'ordre d'expulsion. À ce moment-là, l'usage de la violence était encore interdit et les "récalcitrants" étaient laissés tranquilles.

En juin 1942, le même scénario se répéta. Cette fois, on distribua des formulaires de convocation pour le travail obligatoire sur les chantiers du Mur de l'Atlantique (Organisation Todt, OT). C'est sous escorte policière que les Juifs de l'OT furent embarqués à bord de trains.

Trois mois auparavant, le 17 février 1941, la police anversoise n'avait eu aucun scrupule pour, à la demande de la Sipo-SD d'Anvers, procéder elle-même à l'arrestation de 27 Juifs : « Nous envoyons immédiatement nos agents de police disponibles dans les rues indiquées. » Comme ce fut le cas précédemment, le commissaire en chef, le procureur du Roi et le bourgmestre en avaient été correctement informés. Aucun d'entre eux ne protesta d'une quelconque façon.

Jusqu'alors, la collaboration de la police s'était limitée à de "petites" rafles. Le 15 août 1942, la police anversoise prêta pour la première fois son concours à une rafle de grande ampleur. Cette collaboration se "limita" pour l'essentiel au bouclage des rues. À ce stade, l'arrestation des Juifs en soi était encore l'œuvre des Allemands, plus précisément de la Dienststelle Holm et des Feldgendarmen (des agents de police allemands qui étaient sous l'autorité de la Militärverwaltung). À peine deux semaines plus tard, la police collabora une nouvelle fois à une rafle, qui s'interrompit prématurément. Le lendemain, les Allemands ordonnèrent à la police anversoise de procéder elle-même à l'arrestation massive de Juifs, ordre que les policiers anversois exécutèrent dans les moindres détails. Les Juifs furent littéralement extraits de leur domicile, en ce compris les malades et les blessés. Par ailleurs, cette nuit-là, la police anversoise procéda à un nombre d'arrestations dépassant le quota de 1.000 personnes imposé par les Allemands.

\section{Les chasseurs de Juifs de la SS flamande}

Une première grande rafle de Juifs par des membres anversois de la SS eut lieu en septembre 1942. Le Dienststelle Holm - le Judenabteilung (Service de la question juive) de la Sipo-SD anversois dirigé par Erich Holm - décida de profiter de cette occasion pour y participer. Erich 
Holm mobilisa à cet effet non seulement la Feldgendarmerie, mais le SS-Stormban anversois. Selon des témoignages d'après-guerre de SS, il apparaît que le Stormban anversois fut mis à contribution "en bloc". L'action commença probablement le lundi 21 septembre, voire le samedi 19 septembre.

Karl Virck, l'adjudant d'Erich Holm, dirigeait l'opération. Gustaaf Vanniesbecq choisit comme terrain d'action les maisons communales de Borgerhout, de Berchem et de Deurne où des cartes de ravitaillement pouvaient être obtenues mensuellement. Nous ignorons tout de l'intervention de René Bollaerts - dans l'hypothèse où il y participa.

L'action fut savamment camouflée. Les membres de la Dienststelle Holm et les SS flamands étaient en civils et se mêlèrent au public peu méfiant. Les Feldgendarmen armés attendaient en coulisses. Les arrestations ne visèrent pas uniquement les Juifs. Chaque fois que des Anversois non juifs présentaient des documents d'identification de Juifs cachés, le personnel du service de ravitaillement devait donner ceux-ci à un membre de la Sipo-SD. Les détenteurs de ces documents étaient alors "isolés" et - sous escorte des Feldgendarmen et des SS flamands "obligés" de désigner le lieu de domicile des Juifs en question. Tous les Juifs arrêtés de la sorte furent amenés à la caserne Dossin de Malines avec des camions "réquisitionnés" de firmes de déménagement anversoises.

La période qui suivit immédiatement les rafles dans les services de rationnement peut être qualifiée de "phase chaotique". En effet, c'est alors que différents SS du Stormban anversois ont, sans être accompagnés ni de la Feldgendarmerie ni de la Sipo-SD, passé Anvers au peigne fin à la recherche de Juifs et de biens juifs. Cette "phase chaotique" de pillage fut suivie par une "phase plus structurée", durant laquelle tant Vanniesbecq que Bollaerts jouèrent un rôle important.

Un soir, vers le début d'octobre 1942, l'Untersturmführer August Schollen, le dirigeant du SS-Stormban d'Anvers, convoqua une vingtaine de bénévoles afin de traquer les Juifs, avec la Sipo-SD et la Feldgendarmerie. Parmi ceux qui se proposèrent, il y avait Bollaerts, Vanniesbecq et son comparse Piet Verhoeven. La vingtaine de bénévoles SS était sous la direction du Dienststelle Holm. Selon un témoignage d'après-guerre d'un SS chasseur de Juifs, ils travaillèrent par petits groupes de quatre à cinq personnes, dont un ou deux Feldgendarmen, 
deux membres de la Vlaamse SS et un homme du SD. Au total, il y avait selon toute probabilité 50 à 60 chasseurs de Juifs, parmi lesquels 20 à 30 Feldgendarmen. Lors des rafles d'août, la police anversoise avait agi de la même manière. Toutefois, dans la pratique, un certain nombre de SS traqueront les Juifs sans être accompagnés de la Sipo-SD et de la Feldgendarmerie, et certains agirent même de leur propre initiative.

Ces petits groupes de SS travaillaient apparemment principalement en journée. D'après une déclaration d'un SS chasseur de Juifs, ces actions se déroulaient généralement entre 9 et 16 heures. Toujours selon ce témoignage : «Dès qu'on mettait la main sur une personne [juive], on l'amenait à la Feldgendarmerie du Meir et ensuite à l'avenue Dellafaille [le quartier général de la Sipo-SD d'Anvers]. Le SD venait chercher les Juifs au Meir. ${ }^{59}$ Dans une première phase, les Juifs étaient rassemblés dans les "bunkers" de la Gare centrale à l'avenue De Keyser (De Keyserlei) et, de là, transportés par train vers la caserne Dossin à Malines. Plus tard, on préféra le "système des camions de déménagement" à celui du "train". Pour le transport vers Malines, on fera appel à des firmes de déménagement anversoises. Selon un autre traqueur de Juifs anversois, « partout où on pouvait les trouver, on mettait la main sur les Juifs : à la maison, dans la rue, dans des bâtiments administratifs, etc. $\aleph^{60}$

Francken, de l'organisation d'avant-guerre Anti-Joodsche Front, était particulièrement satisfait de la traque faite aux Juifs. Il écrivit à un ami anversois, également ancien membre de l'Anti-Joodsch Front : «Que tu aies aidé au nettoyage de Juifs ne m'étonne pas du tout, bien qu'il y en ait encore toujours à Anvers. N'a-t-on donc pas prévenu les Sinjoren [les Anversois "de souche"] que ceux qui cacheraient des Juifs, partageraient le sort de leurs protégés ? Ou se trouvent-ils plutôt en dehors de la ville, ce qui semblerait être souvent le cas ? ». " ̇̀ Bruxelles », poursuit Francken, « nous avons aussi organisé différentes chasses aux Juifs et toujours fait de belles prises. Je suis vraiment curieux de découvrir le nouveau paysage anversois. L'air doit y être bien plus frais. $\aleph^{61}$

\footnotetext{
${ }^{59}$ Auditorat militaire, Dossier Felix Lauterborn et consorts.

${ }^{60}$ Ibid.

61 Ceges, Archives Anti-Joodsch Front, Courrier de Francken à Karel Meeus, 26.10 .1942 .
} 
Francken avait entretemps déménagé vers Bruxelles-ville, où il faisait partie de la Judenabteilung de la Sipo-SD. Il était en même temps membre de l'Algemeene SS-Vlaanderen et de DeVlag. C'était un traqueur de Juifs acharné : « Dans le courant de la semaine dernière », fitil savoir à ce même ami, « je suis personnellement allé au Stelle de la police SS parce que j'avais préparé une liste d'affaires juives à régler. Vraiment, je ne pouvais concevoir de laisser ces affaires juives en souffrance. $\aleph^{62}$

\section{Les arrestations}

Fin octobre, début novembre 1942, quelques fidèles furent choisis dans le groupe formé d'une vingtaine de SS. N'étant pas rétribués, les SS compensaient en dévalisant leurs victimes. Selon le témoignage de Janssens, tout citoyen anversois qui dénonçait des Juifs recevait une prime de 100 francs belges, mais la majorité des dénonciations se faisait néanmoins par lettre anonyme.

Felix Lauterborn, 47 ans, allait désormais occuper le devant de la scène. Cet ancien photographe et journaliste sportif, membre de Volksverwering bien avant la guerre, devint sous l'Occupation Beschermend Lid (Membre protecteur) des Algemeene SS-Vlaanderen et le confident d'Erich Holm (« un grand roux avec des taches de rousseur »), le dirigeant de la Judenabteilung anversoise. Lorsque Lauterborn était en état d'ébriété, il devenait ingérable. Avant-guerre, de nombreux procès-verbaux furent dressés à son encontre.

Le fait qu'Emiel Janssens exploitait un café était une aubaine. Felix Lauterborn dit à ce sujet : « J'étais souvent dans le café de Janssens. [...] Holm était au courant de cela et chaque fois qu'il voulait nous joindre, il téléphonait d'abord là. Il arrivait qu'il vînt nous y chercher. ${ }^{63}$ Il est évident que de nombreuses arrestations se firent dans un certain état d'ébriété, avec toutes les conséquences que cela put avoir pour les victimes.

Par ailleurs, Gustaaf Vanniesbecq, qui était en bons termes avec Otto Desselmann, le dirigeant du SD anversois, sut gagner et conser-

62 Ceges, Archives Anti-Joodsch Front, Courrier d'E. Francken à Karel Meeus, 6.7.1943-8.4.1944.

63 Auditorat militaire, Dossier Felix Lauterborn et consorts. 
ver la confiance de ses supérieurs dans sa fonction de traqueur de Juifs. Il n'est pas étonnant qu'il formât rapidement un duo avec son ami Otto Desselmann. Les équipes de Lauterborn et de Vanniesbecq travaillaient cependant régulièrement ensemble. En principe, lors des arrestations, ils étaient toujours accompagnés d'un SS-Dolmetscher flamand ou d'un membre allemand du Dienststelle, comme Erich Holm. Parfois, un chauffeur (flamand) du Dienststelle prenait part aux opérations.

L'arrestation des Juifs se déroulait selon Felix Lauterborn de la façon suivante : «Nous allions chercher les Juifs à des endroits qui nous étaient préalablement indiqués par le Dienststelle [le Judenabteilung], qui recevait régulièrement des adresses par le biais de lettres anonymes, de dénonciations et d'autres sources d'information. Nous n'étions jamais renseignés quant à la source de ces adresses. " Les dénonciations auraient donc été à la base des arrestations des Juifs à Anvers. À en croire Lauterborn, « sur la centaine de Juifs arrêtés [...], quatre-vingts furent dénoncés par lettres anonymes. ${ }^{64}$

La plupart des actions se déroulaient alors plutôt la nuit. Invectiver les victimes et leur distribuer des coups faisait partie de la panoplie d'intimidations, mais, selon Felix Lauterborn, "pas de telle façon à ce que l'on puisse dire qu'il s'agissait de "passages à tabac" ". ${ }^{65}$ En vérité, la brutalité était pratiquée et il y eut également des attouchements sexuels. Lauterborn et ses acolytes n'avaient aucun scrupule à pousser des femmes et des enfants dans les escaliers ou à les jeter dans des camions en attente. Ceux qui essayaient encore de fuir étaient abattus. Les maisons des Juifs arrêtés étaient ensuite scellées par Lauterborn et ses comparses, dans l'attente de la venue du Devisenschutzkommando. Mais déjà lors des actions, les équipes de Vanniesbecq et Lauterborn volaient ce qu'ils pouvaient emmener. L'unique différence avec la période d'action de la vingtaine de SS fut que les équipes de Lauterborn et de Vanniesbecq dépouillaient leurs victimes de manière moins ostensible.

Le transport des Juifs arrêtés par les bandes Vanniesbecq et Lauterborn se déroulait des façons les plus diverses. Selon toute probabilité, cela se passait en journée, généralement par des camions de déménage-

64 Ibid.

65 Ibid. 
ment. Certaines victimes furent simplement mises dans le tram où elles furent enchaînées au vu des personnes présentes. Un certain nombre d'arrestations se firent même en taxi. Gustaaf Vanniesbecq se déplaçait souvent en moto pour ses opérations de traque avant que des membres de la Sipo-SD ou de la Feldgendarmerie n'arrivent sur place. La voiture de Karl Vierk, l'adjoint d'Erich Holm, se révélait également “pratique".

Dans de nombreux cas, les victimes n'étaient pas transportées directement vers la caserne Dossin à Malines, mais d'abord écrouées à la prison de la Ville d'Anvers rue des Béguines, au quartier général de la SS d'Anvers dans la rue Quellin (juste à côté du "quartier juif", près de la Gare centrale), ou au quartier général de la Sipo-SD, avenue Dellafaille. Souvent, les détenus passaient par plusieurs de ces lieux.

Les enfants dits "abandonnés", dont les parents avaient été arrêtés, étaient transférés à l'orphelinat de la Longue rue d'Argile. Dans le cas où les parents n'avaient pas encore été déportés, René Bollaerts et Paul Martens se chargeaient d'amener les enfants appréhendés à la caserne Dossin à Malines, d'où ils étaient déportés vers Auschwitz.

Gustaaf Vanniesbecq ayant après-guerre pu échapper à la justice, nous ignorons à peu près tout de la façon dont il agissait. De surcroît, après la Libération, des membres de la Witte Brigade (Brigade blanche) saccagèrent son domicile et brûlèrent ses lettres et documents dans la rue ${ }^{66}$. Mais sa façon d'agir était indubitablement comparable à celle de René Bollaerts (« un petit noiraud»). Le 26 juin 1943, vers midi, Bollaerts et Pol Martens (« un grand blond »), habillés en civil, vinrent sonner au 35 Belgiëlei, chez Henriette Van Welde, une femme âgée de 52 ans. Elle était soupçonnée de cacher des Juifs. La fouille du domicile de Van Welde leur livra un homme, une femme et deux enfants, probablement des Juifs hongrois. Selon Van Welde, «le long blond s'est écarté. Entretemps, le petit noiraud m'a frappée violemment avec une clef de manœuvre du poêle. Ensuite, ils m'ont traînée dehors et emmenée dans une camionnette rouge appelée sur place par le long blond, et puis je fus transférée rue des Béguines [la prison an-

66 Auditorat militaire, Dossier personnel de Gustaaf Vanniesbecq, Pv Sûreté de l'État, 5.2.1945, $\mathrm{n}^{\circ} 1737$. 
versoise]. » ${ }^{67}$ Entretemps, Martens avait volé chez Van Welde « une valise d'argent » pour une valeur de $6.800 \mathrm{fr}$.

Certaines arrestations étaient dignes "d'un film d'action", par exemple l"“opération magasin de tabac" du 17 mars 1943. Josephine Hartog, la compagne juive du négociant de tabac Hendrik Kusters fut arrêtée au 10 Charlottalei. Les auteurs de l'arrestation étaient Felix Lauterborn, Miel Janssens, « un long blond » (Paul Martens) et « un cheveux noirs bouclés » (René Bollaerts). Kusters témoignera qu' « après avoir mis les scellés sur mon armoire à linge et ma garde-robe, ils ont emmené Josephine Hartog ensemble avec de nombreuses autres victimes dans une voiture-camion. ${ }^{68}$ Peu après, apparut chez Kusters, madame Josée K., qui très vite gagna sa confiance : « Elle me disait qu'elle avait déjà tant fait pour empêcher des Juifs et d'autres Belges d'être emmenés en Allemagne. Elle m'aiderait aussi, également pour le ménage, les courses, etc. Elle apporterait également à Malines Dossin un colis de victuailles et autres et me dit que Josephine Hartog était là. ${ }^{69}$ Finalement, Josée se fit embaucher comme nouvelle gérante du commerce de cigares, mais elle se révéla être un agent à la solde d'Erich Holm, ce qui permit à Lauterborn et ses copains d'avoir dorénavant libre accès au magasin.

La bande d'Erich Holm avait d'une manière ou d'une autre appris qu'Hendrik Kusters avait une large clientèle juive. Il se peut que Felix Lauterborn et ses comparses aient lors de la perquisition trouvé une liste des clients de Hendrik Kusters, sur laquelle figuraient pas moins de cinq cents noms juifs. Selon Lauterborn, « sur ordre de Holm, Josée K. servait les clients, tandis que nous attendions derrière un rideau. Elle devait nous livrer les Juifs qui entraient. Le mode opératoire était le suivant : lorsqu'un Juif entrait, un signal secret était donné, qui consistait à dire à voix haute une phrase convenue d'avance, par exemple: "cela fait longtemps que je vous ai pas vu". Nous savions alors qu'il y avait un Juif dans le magasin. Dès qu'il sortait, nous le suivions de près et nous l'arrêtions un peu plus loin dans la rue. » « Je n’y étais jamais seul », ajoute Lauterborn, « Martens, Janssens, Bol-

\footnotetext{
67 Auditorat militaire, Dossier Felix Lauterborn et consorts, Audition de Henriette Van Welde, 1945-1946.

68 Ibid.

${ }^{69}$ Ibid.
} 
laerts et possiblement Vanniesbecq ont également assuré une surveillance dans ce magasin. $»^{70}$

Certains Anversois ne supportèrent pas plus longtemps d'assister à cette chasse aux Juifs et le firent savoir clairement. À Anvers, véritable foyer d'antisémitisme avant et pendant l'Occupation, il fallait une bonne dose de courage pour l'exprimer. Ainsi, Raymond Tanghe, un exportateur né à Ostende, alla jusqu'à s'attaquer physiquement à la bande de Lauterborn. C'est jusqu'à présent l'unique exemple connu, mais qui vaut la peine d'être mentionné. Le 22 octobre 1942 vers deux heures de l'après-midi (dans une autre déclaration, il donne comme date le 22 novembre 1942), Tanghe fut témoin d'une arrestation avenue Plantin Moretus. Les auteurs en étaient Janssens, Bollaerts, le Dolmetscher Joris Wiethase et Vanniesbecq. Les déclarations d'aprèsguerre de Tanghe donnent en général une image pas très glorieuse de certains Anversois et constituent autant de témoignages de la complicité des firmes de déménagement anversoises : "Je vis sortir une femme très âgée tenant à la main une fillette [...]. Au même moment un individu la suivait et lui donnait force coups de pied et poing. Une telle colère m'a pris, que j'ai immédiatement traversé la rue violemment et apostrophé cette ignoble brute. [...] Pendant que j'insultais cet individu, deux plus jeunes [...] sortirent également de la même maison. À eux deux ils se précipitèrent sur moi sur l'ordre du premier. Ils essayèrent de me conduire et de m'embarquer dans leur camion de déménagement (d'une firme de Mariabourg). À coups de pied et poing, je me suis défendu. À tel point que ces deux Sicherheitsdienst furent hors combat. Toutefois le cafetier [Janssens] a sorti un revolver. » Tanghe ne capitula pas pour autant immédiatement : "Venant vers moi, je n'avais plus qu'à lever les bras. S'étant approché trop près de moi, je lui ai donné un tel coup de pied dans le ventre qu'il est tombé. J'en ai profité pour prendre le large. Mais quelques instants après une auto allemande me poursuivait. M'étant caché dans une fabrique de la rue de la Province - la concierge fit un tel tumulte que l'auto s'arrêta, et je fus livré. [...] Je fus embarqué dans le camion avec une trentaine

${ }^{70}$ Auditorat militaire, Dossier Felix Lauterborn et consorts. 
de Juifs - hommes et femmes et enfants. " $^{71}$ Lorsque Tanghe fit la remarque à Bollaerts que celui-ci n'avait absolument aucune compassion pour ces Juifs arrêtés (« ces pauvres gens »), Bollaerts lui répondit : « Nous n'avons aucune pitié pour un tel peuple. » Et Janssens aurait ajouté : «Vous avez de la chance que mon revolver se soit enrayé. »

\section{Libération et après-guerre}

Après la guerre, René Bollaerts, Antoon Lint et Gustaaf Vanniesbecq furent arrêtés, Bollaerts était revenu en Belgique. Arrêté à Gand et écroué au centre d'internement de Hemiksem, il simula une attaque d'épilepsie pendant l'enquête judiciaire : «Lorsque ceci échoua, il insulta le personnel [du centre d'internement] de la manière la plus grossière. " $^{72} \mathrm{Au}$ procès collectif de Lauterborn et ses acolytes, Bollaerts fut condamné à mort par le tribunal de première instance, tout comme Lauterborn, Janssens, Paul Martens et Joris Crespin. Le procès Lauterborn et consorts est l'un des rares procès de collaborateurs belges où la persécution des Juifs fit l'objet d'une attention particulière ${ }^{73}$. Janssens, Crespin, Bollaerts et Lauterborn firent appel. Les peines de Bollaerts et Crespin furent commuées en emprisonnement à perpétuité. La peine de mort fut conservée pour Lauterborn et Janssens. Martens fut condamné à mort par contumace, la justice ignorant qu’il était mort aux Pays-Bas vers septembre 1944. Ce mois-là, il s'était enfui de la Sipo-SD d'Anvers pour aller à Apeldoorn, où avec d'autres membres de la Sipo-SD il se livra à des crimes de guerre.

René Lambrichts, Jozef Vranken, Constant Van Dessel et Ward Hermans furent également condamnés à mort. Tous firent appel, mais seul Lambrichts vit sa peine commuée en peine d'emprisonnement à vie. Cependant, aucun des condamnés à mort ne fut exécuté. Vranken, Van Dessel et Janssens furent libérés de façon anticipée en 1963, et

\footnotetext{
71 Auditorat militaire, Dossier Lauterborn et consorts, Courrier de Raymond Tanghe au Procureur du Roi d'Anvers, 9.10.1944 et pv d'audition de Raymond Tanghe, 30.10.1945.

72 Auditorat militaire, Dossier René Bollaerts, Courrier du directeur du centre d'internement de Hemiksem au substitut de l'auditeur militaire, 14.11.1945.

${ }^{73}$ Lire à ce sujet : M.-A. Weisers, Juger les crimes contre les Juifs : des Allemands devant les tribunaux belges, 1941-1951, thèse de doctorat en histoire, ULB, 2014.
} 
Lauterborn succomba à une crise cardiaque dans la prison de Louvain en 1957.

À l'approche des troupes alliées en Belgique, le dimanche 3 septembre 1944, Gustaaf Vanniesbecq prit la fuite vers l'Allemagne dans une carriole tirée par un cheval. Sa femme et son enfant étaient déjà partis en train. Arrêté, il réussit à s'évader de sa cellule avant d'être jugé. Il fut condamné à mort par défaut et s'enfuit vers la France, où il entrera en service auprès de la Direction de la Surveillance du Territoire (DST), qui avait pour mission de dépister les collaborateurs qui avaient travaillé pour l'Abwehr... Il s'installa ensuite en Argentine pour se retrouver finalement en Espagne, où demeurait déjà son épouse. Il y fit d'abord neuf mois de prison avant de travailler comme traducteur à Madrid. Il acquit après un certain temps la nationalité espagnole. D'Espagne, il collabora au périodique d'extrême droite $D e$ Vrijbuiter (qui vit le jour en 1964), l'organe de la section gantoise du Vlaamse Militantenorde (VMO). Il soutenait différentes initiatives nationales-socialistes et devint le représentant officiel en Espagne du Sint-Maartensfonds, une association caritative pour les anciens combattants, proche des milieux collaborationnistes ${ }^{74}$.

En 1966, Gustaaf Vanniesbecq se mit en contact avec Roeland Raes, qui appartenait à l'aile droite de la Volksunie, était actif au sein de l'organisation d'extrême droite Were Di (Défends-toi) et se fit connaître plus tard pour ses positions négationnistes et comme sénateur du Vlaams Blok. Vanniesbecq lui demanda de l'aider à mettre sur pied « une sorte de comité de libération flamand à l'étranger », le but étant de « libérer complètement la Flandre de la Belgique, et ce en collaboration avec des Wallons ». L'argent ne constituait pas selon lui un obstacle et il espérait pouvoir se mettre en contact avec René Lagrou. Bien que Raes considérait ce projet comme « très stimulant », celui-ci ne vit pas le jour. Un autre Flamand notoire "exilé" à l'étranger répondit à Raes que Vanniesbecq n'était rien de plus qu'un « hurluberlu ». Le 12 septembre 1971, Vanniesbecq décéda à Madrid. Tant De Vrijbuiter (Le Flibustier), Berkenkruis (La Croix du bouleau), le journal des anciens du Front de l'Est, que Broederband (Fraternité), porte-

\footnotetext{
${ }^{74}$ Fr. Seberechts - Fr.-J. Verdoodt, « Leven in twee werelden. Belgische collaborateurs en de diaspora na de Tweede Wereldoorlog », dans Wetenschappelijke tijdingen op het gebied van de geschiedenis van de Vlaamse Beweging, 60, 1, 2011, pp. 140-141.
} 
parole des Amicales des Victimes nationalistes flamandes de la Répression (Vriendenkringen van Vlaams-nationale repressieslachtoffers) lui consacrèrent un in memoriam ${ }^{75}$. Après sa mort, sa veuve continua à soutenir financièrement la Volksunie ${ }^{76}$.

Antoon Lint fut condamné à 20 ans de prison, puis réhabilité dans le courant des années 1950. Après sa libération anticipée au début des années 1950, Bollaerts, qui avait maltraité tant de Juifs, choisit d'exercer le métier de kinésithérapeute.

\section{Conclusion}

Au cours des années 1930 apparut à Anvers un grand nombre d'organisations antijuives et d'inspiration nationale-socialiste. Presque tous ces groupuscules avaient leur berceau et leur point d'ancrage dans la métropole flamande. Contrairement au reste du pays, Anvers connut un rassemblement des forces antijuives.

Les positions antisémites venaient surtout des sphères d'influence du parti catholique, des organisations d'indépendants et des mouvements favorables à l'Ordre nouveau. À partir de 1933, avec l'arrivée de réfugiés fuyant l'Allemagne nazie, l'animosité à l'égard des Juifs monta d'un cran : les meetings antijuifs se multiplièrent, la presse catholique se mit à parler de la communauté juive en des termes de plus en plus malveillants et certains groupuscules antisémites n'hésitèrent pas à recourir à la violence physique. La radicalisation générale atteint un premier sommet dans les échauffourées d'août 1939, qui mobilisèrent une masse de gens et que toléra pratiquement l'ensemble de la presse catholique anversoise.

Au début de l'Occupation, les Juifs étaient donc déjà stigmatisés par de larges couches de la population anversoise. La victoire allemande éveilla les appétits des dirigeants et des militants des groupes antisémites et nationaux-socialistes, impatients de passer à l'action. Un certain nombre d'animateurs de ces organisations vont participer activement aux persécutions des Juifs, collaborer avec la Sipo-SD et se rendre coupables de rackets envers leurs victimes juives. Comme

\footnotetext{
75 Ibid.

76 Nous remercions Philippe Van Meerbeeck, ancien collaborateur de Maurice De Wilde, pour ces informations.
} 
l'illustrent les parcours individuels des personnes évoquées, il fut extrêmement facile aux nationalistes flamands de franchir le pas de la collaboration. Les organisations nationalistes flamandes soutenaient sans réserve la politique antijuive des Allemands, appelaient fréquemment à prendre des mesures encore plus radicales et constituaient un vivier où se recrutaient les "chasseurs de Juifs". Ces collaborateurs anversois allaient enfin former une importante force de complément, aux côtés des effectifs allemands, lors des rafles antijuives.

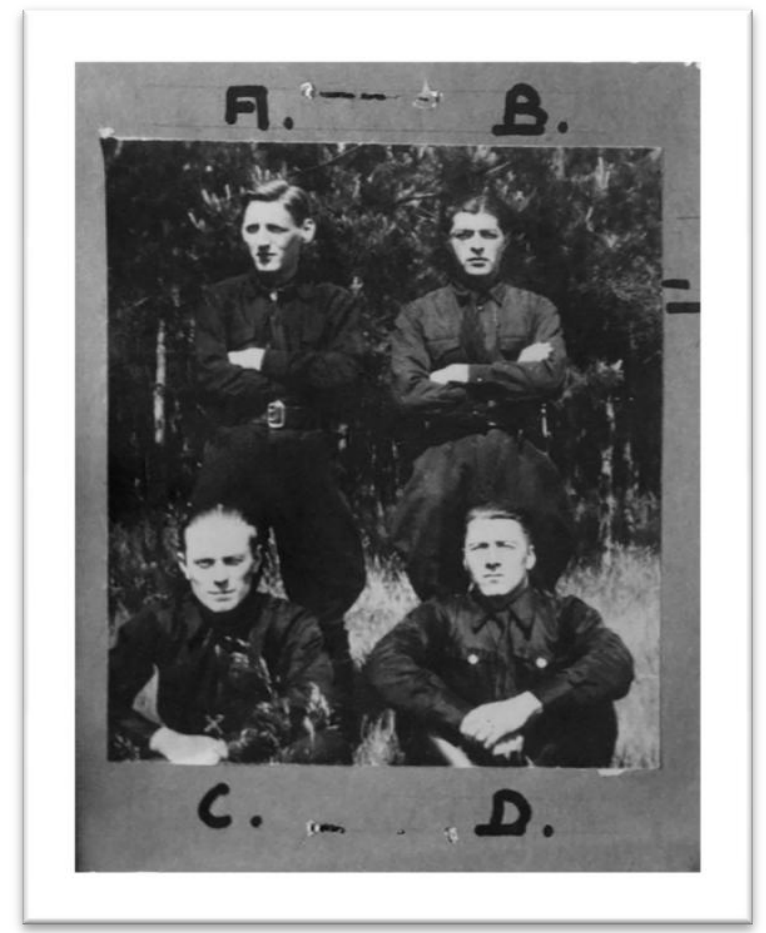

Debout de gauche à droite : Antoon Lint et René Bollaerts. Assis, à droite : Gustaaf Vanniesbecq. (C) Felixarchief 
Cahiers de la Mémoire contemporaine - Bijdragen tot de eigentijdse Herinnering - XII - 2016
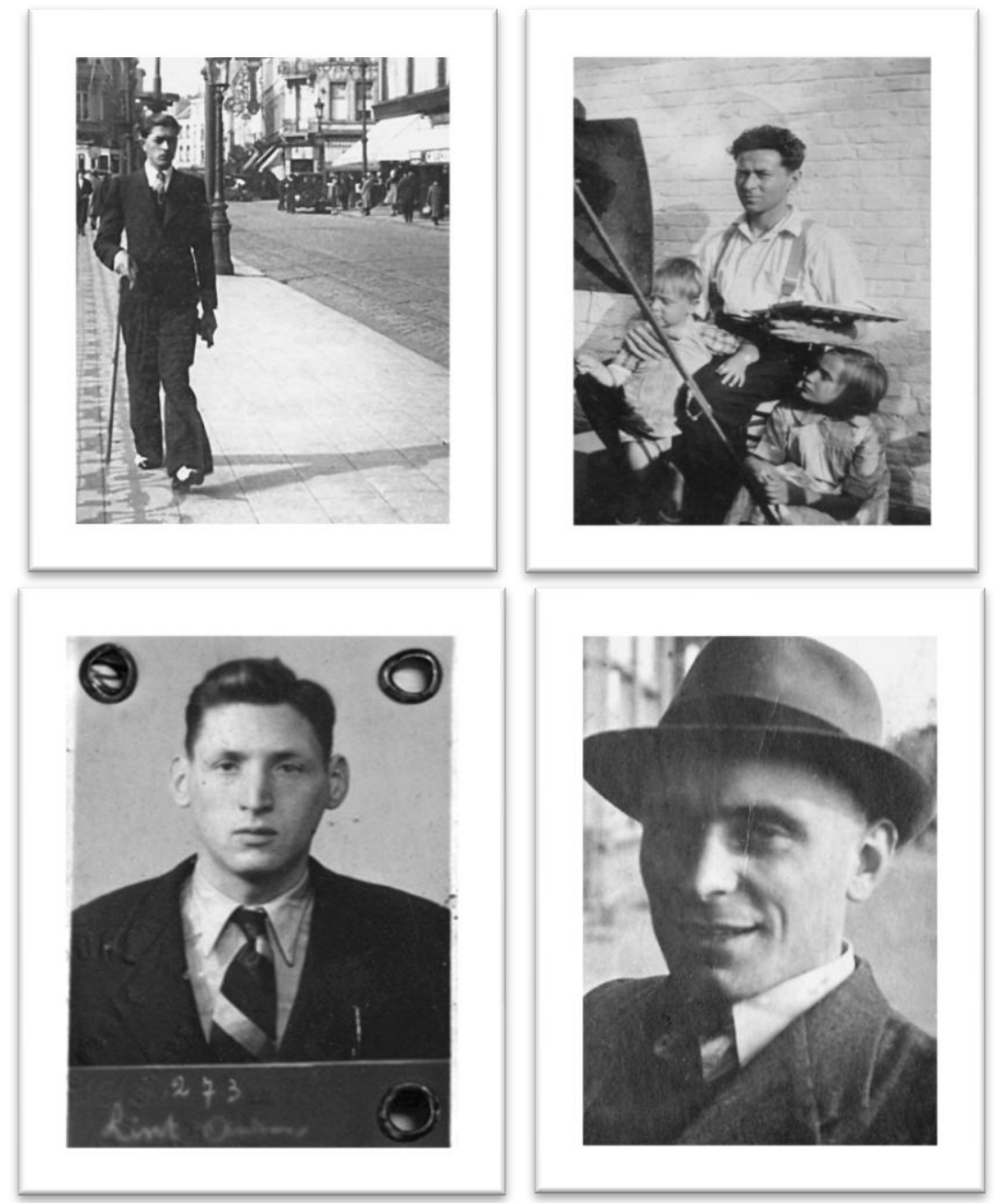

En haut : René Bollaerts.

En bas, de gauche à droite : Antoon Lint et Gustaaf Vanniesbecq. 
Cahiers de la Mémoire contemporaine - Bijdragen tot de eigentijdse Herinnering - XII - 2016
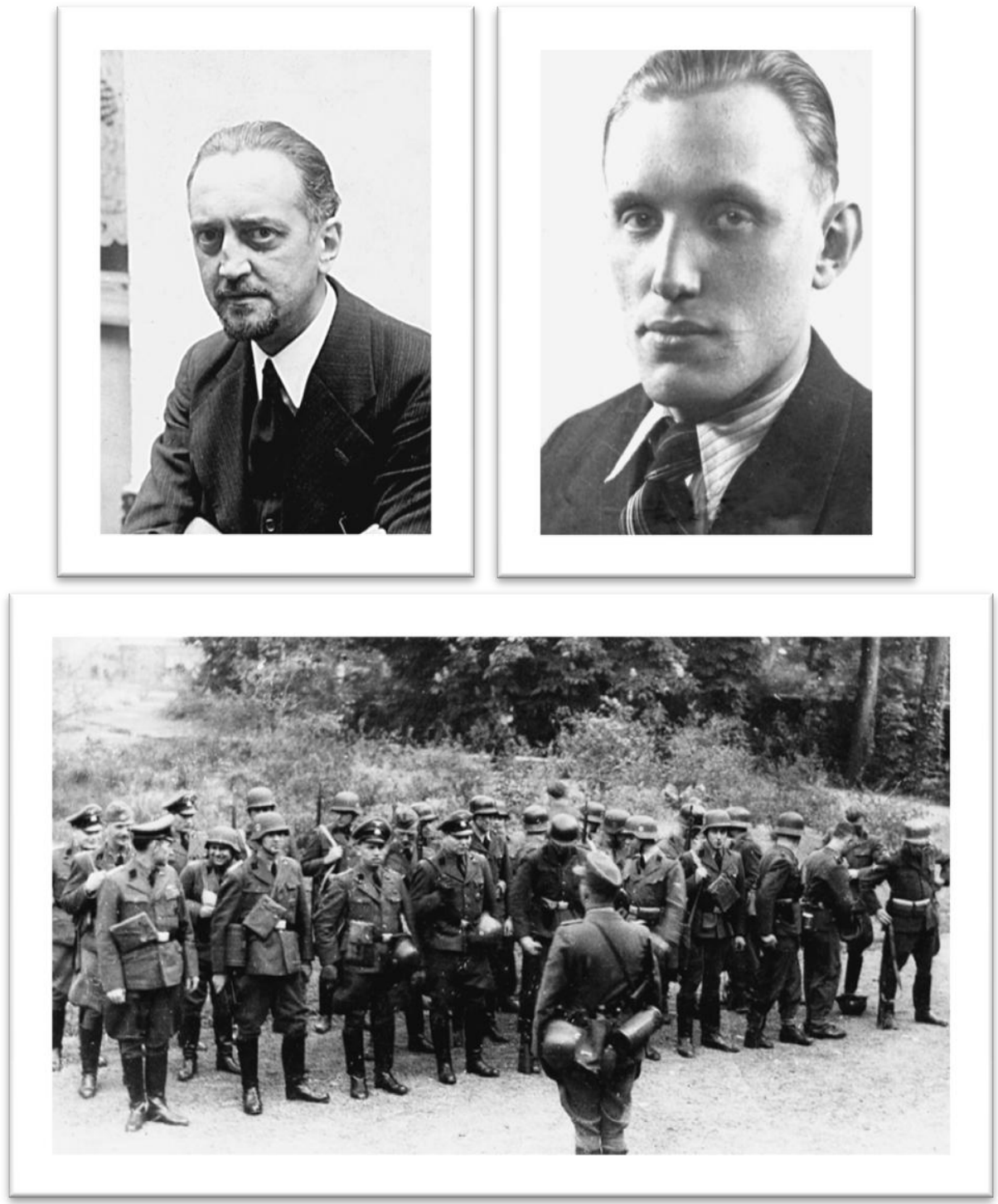

En haut, de gauche à droite : Felix Lauterborn et Emiel Janssens. En bas : la Sipo-SD d'Anvers. 


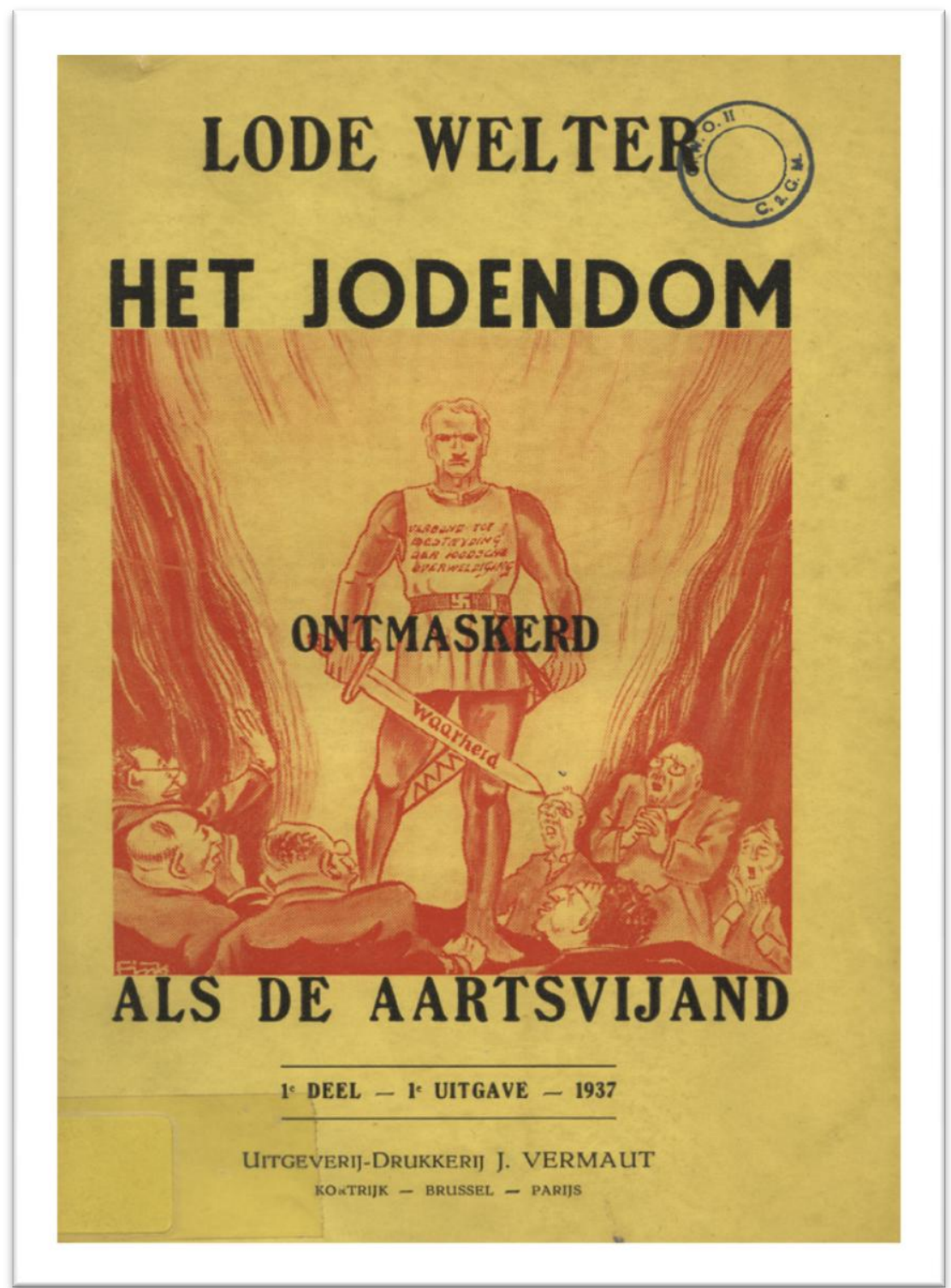

Lode Welter et Emiel Francken publièrent ensemble en 1937

Het Jodendom ontmaskerd als de aartsvijand, une traduction du pamphlet antisémite Les Protocoles des Sages de Sion. 


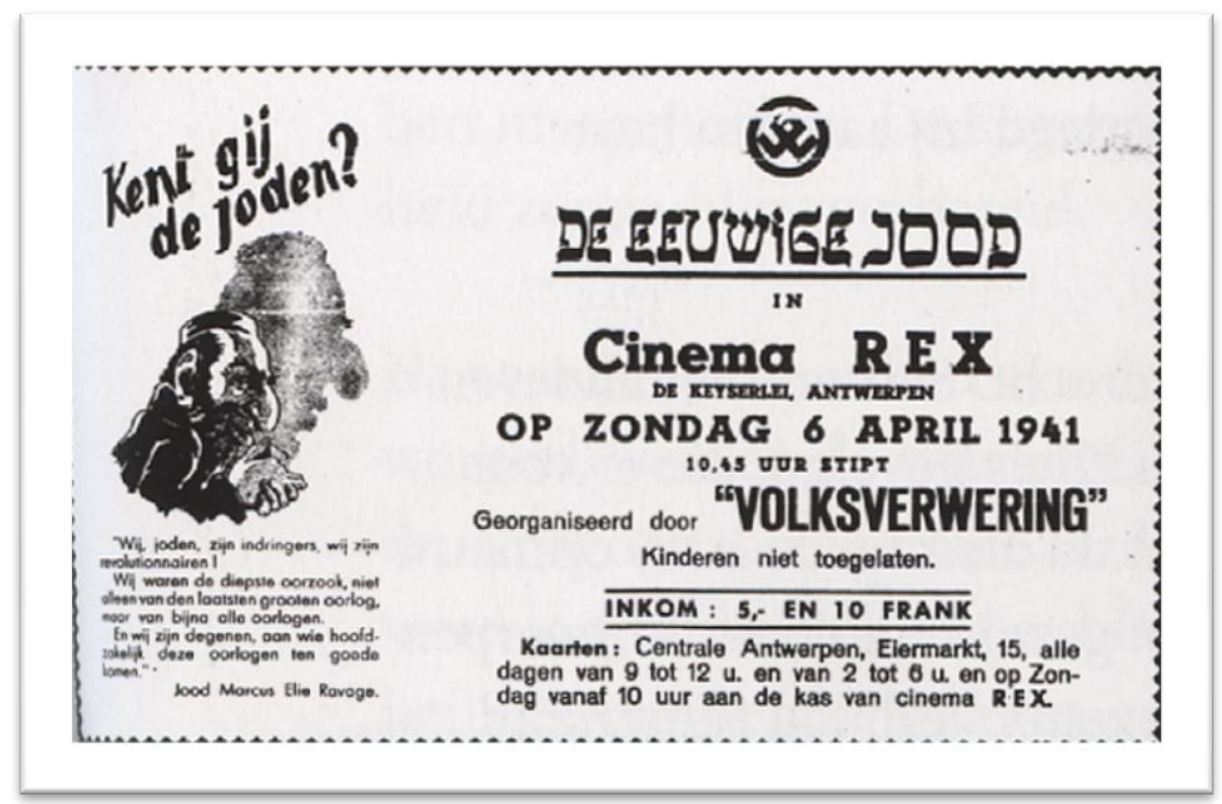

Le 6 avril 1941, l’organisation antijuive Volksverwering programma au cinéma Rex la projection du film antisémite Der Ewige Jude du réalisateur allemand Fritz Hippler. 